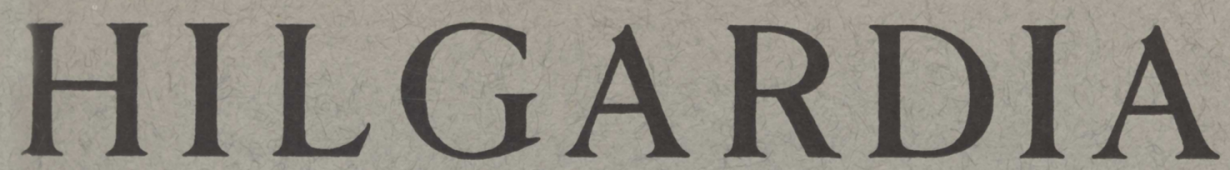

A Journal of Agricultural Science Published by the California Agricultural Experiment Station

\title{
A GUIDE TO THE SPIDER MITES OF COTTON
}

EDWARD W. BAKER and A. EARL PRITCHARD 
Spider mites are increasingly serious pests of cotton and forage crops. Because the acaricides now being developed are often highly selective among species, entomologists concerned with the control of these pests need to know the particular species they are dealing with. This report has been prepared to aid them. Both field guides and taxonomic keys are given. Suggestions are offered on how to sample, how to prepare slides, and what diagnostic characters to look for.

One new species from Nicaragua is described, and new synonymy is noted for several others. The species treated-all those reported from cotton in North and Central America-are:

Petrobia latens (Müller)

Paratetranychus peruvianus McGregor

Paratetranychus mcgregori new species

Tetranychus pacificus McGregor

Tetranychus schoenei McGregor

Tetranychus canadensis (McGregor)

Tetranychus bimaculatus Harvey

Tetranychus atlanticus McGregor

Tetranychus marianae McGregor

Tetranychus desertorum Banks

Tetranychus tumidus Banks

In addition, some species reported from cotton in other parts of the world are noted, and a new combination, Paratetranychus stenoperitrematus (Ugarov and Nikolskii), is given for one of them. 


\section{H I L G A R D I A}

A Journal of Agricultural Science Published by

the California Agricultural Experiment Station

VOL. 22

JULY, 1953

No. 7

\section{A GUIDE TO THE SPIDER MITES OF COTTON}

\section{EDWARD W. BAKER ${ }^{2}$ and A. EARL PRITCHARD ${ }^{3}$}

\section{INTRODUCTION}

SPIDER MITES, or red-spiders, are among the more serious pests of cotton wherever it is grown. During recent years economic entomologists have been increasingly concerned with these mites, partly because many of the more obvious cotton pests are now easily controlled. Moreover, some of the new insecticides are often detrimental to predaceous enemies of spider mites, or render the plants more susceptible to the mites. Then, too, the movement of cotton to the irrigated Southwest emphasizes the mite problems, because they tend to be more serious in this arid region.

Organic chemicals are being tested and used extensively for spider-mite control on cotton, but they are often found to be effective for the control of only certain species or to vary in their degree of effectiveness among species. Smith and Bryan (1951) have emphasized differences in the reaction of spider mites on cotton to many of the acaricides available.

It is thus important that the entomologist make accurate determinations of the spider mites with which he is concerned, either in experimental work with chemicals or in making recommendations for their control. This guide should aid him in making the identifications.

Spider mites attacking cotton in the United States have received more attention from the acarologist than those in other cotton-growing areas of the world, and this guide is primarily concerned with the North American mites. But since species found on cotton in Central America are potential emigrants to agriculture in the southern United States, they are included.

Spider mites are often serious pests of forage crops, and entomologists concerned with such plants have requested a guide for identification of their spider-mite pests. The present article contains information on all tetranychid mites known from forage crops in the United States and Canada except for Bryobia praetiosa Koch. This distinctive species was considered in a previous article (Pritchard and Baker, 1952).

${ }^{1}$ Received for publication March 10, 1953.

${ }^{2}$ Acarologist, United States Department of Agriculture, Agricultural Research Administration, Bureau of Entomology and Plant Quarantine.

${ }^{3}$ Associate Professor of Entomology, University of California, Berkeley, and Associate Entomologist in the California Agricultural Experiment Station. 


\section{SAMPLING}

Cotton is often infested with several species of spider mites. The coloration or markings of the body of adult females may be indicative of the species involved, and the feeding, spinning, or defoliation habits are often important aids for species recognition in the field.

These characteristics should be taken into consideration when selecting mite samples. A number of small samples will often give a better evaluation of the mite infestation of a cotton field than a single large or composite sample.

Infested leaves may be gathered for sampling purposes. They should be placed in plastic refrigeration bags, ice-cream cartons, or paper bags for laboratory examination. Refrigeration may be used for a week or two for preservation of mites on the foliage, if samples of adult males and females are not immediately selected for preservation in alcohol.

Ordinarily the infested cotton leaves are too large for preservation in small bottles, and only sections of the infested leaves should be used for samples to be placed in a vial for preservation. The vial should contain from 60 to 85 per cent ethyl alcohol. It is important not to cram a large leaf section into a small vial.

\section{SLIDE PREPARATION}

Hoyer's mounting medium is the most practical for spider mites. It consists of the following ingredients:

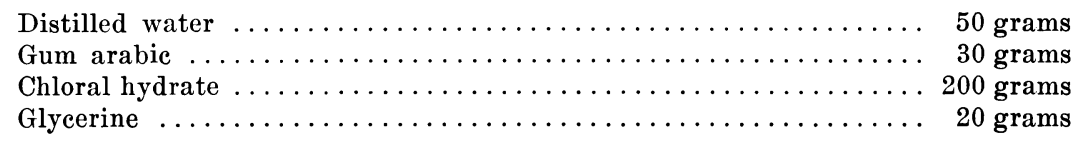

The materials should be mixed at room temperature in the sequence listed. Stirring may be necessary over a period of several days. The solution may be hastened with careful warming over a water bath, but it is not known whether this affects the lasting qualities of the medium.

Live mites or alcoholic specimens may be placed directly into a drop of Hoyer's medium on the slide. Females are ordinarily mounted with the dorsal side up. If the slide is warmed on a desk lamp after the slide cover is in place, the legs will straighten out and a certain amount of clearing will take place. Males must be oriented laterally, and best results are obtained when only one specimen is mounted on a slide. If the slide is heated on a desk lamp before the cover glass is placed, it is easier to compress the male with tiny needles; and a perfect lateral position of the specimen - or at least of the aedeagus - may then be obtained by rolling the cover slip while observations are being made with the compound microscope.

\section{DIAGNOSTIC CHARACTERS}

The identification of cotton spider mites with the aid of a compound microscope is based on the differentiation of relatively few characters. A $43 x$ objective lens with a $10 \times$ ocular ordinarily gives ample magnification for discerning these characters. 
The fore tarsus bears two pairs of intimately associated setae that are called the duplex setae. The location of the duplex setae is important for identification.

The end of the tarsus bears a pair of tenent (knobbed) hairs on each side, each pair representing nearly all that remains of a true claw. The empodium

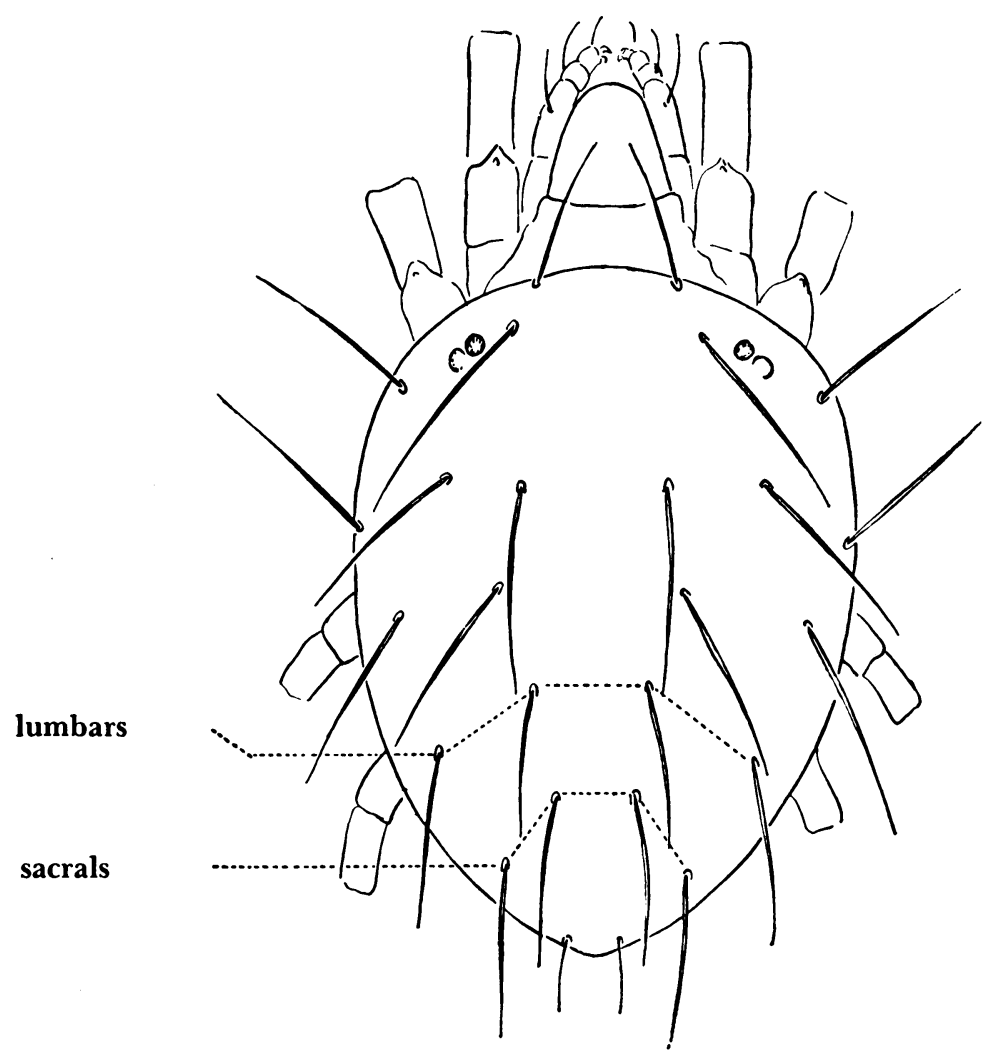

Fig. 1. A Tetranychus spider mite, showing location of the lumbar and sacral setae.

is located between these tenent hairs, and its structure is of taxonomic value. It is clawlike with ventral rows of tenent hairs in Petrobia (fig. 2); clawlike with proximoventral simple hairs in Paratetranychus (fig. 8); and the empodial claw is strongly reduced or rudimentary with the simple hairs remaining in Tetranychus (fig. 13).

The pattern of the integumentary striae on the dorsum of females belonging to the genus Tetranychus is important for distinction of certain groups of species. Striations in the area between the inner lumbar and inner sacral setae (fig. 1), are of particular significance.

The final identification is usually based on the shape of the aedeagus. Males must be mounted laterally to see the outline of this simple but very diagnostic structure. 


\section{KEY TO GENERA KNOWN FROM COTTON}

1. Empodium clawlike with several pairs of simple hairs proximoventrally or else consisting only of simple hairs; anterior legs of adult female not obviously lengthened... 2

-. Empodium clawlike, with two rows of ventrally directed, knobbed hairs; anterior legs of adult female much longer than other legs; dorsal setae of body much shorter than

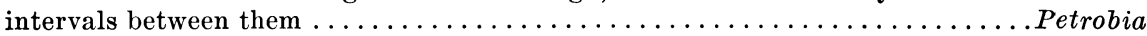

2. Empodium clawlike and about as long as the proximoventral hairs.....Paratetranychus

-. Empodium with the median, clawlike portion much shorter than the proximoventral hairs and usually rudimentary $\ldots \ldots \ldots \ldots \ldots \ldots \ldots \ldots \ldots \ldots \ldots \ldots \ldots \ldots \ldots$ Tetranych

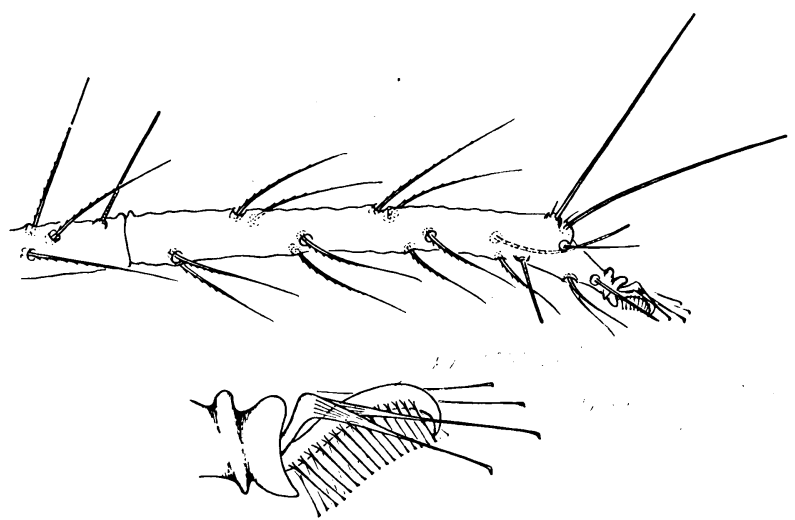

Fig. 2. Petrobia latens : tarsus I of female, with enlargement of empodial appendages.

\section{GENUS PETROBIA MURRAY}

Petrobia Murray, 1877, Econ. Ent., Apt., p. 118. Type of genus, (Trombidium lapidum Hammer) = Petrobia latens (Müller); by original designation and monobasic.

Tetranobia Banks, 1917, Ent. News 28: 194. Type of genus, (Tetranobia longipes Banks) = Petrobia latens (Müller); monobasic.

The genus Petrobia includes only one species, and it is of economic importance. This species has been encountered occasionally on cotton seedlings in California and Texas.

\section{Petrobia latens (Müller) Brown Wheat Mite}

(Figs. 2, 3, 4)

Acarus latens Müller, 1776, Zool. Dan. Prodr., p. 187.

Acarus praegnans Schrank, 1781, Ins. Austr., p. 520.

Acarus petrarum Fourcroy, 1785, Ent. Paris 2: 529.

Tetranychus anauniensis Canestrini, 1889, Atti Reale Ist. Ven. Let. Sci. Arti (ser. 6) 7 :

503. New synonymy.

Trombidium lapidum Hammer, 1894, in: Hermann, Mém. Apt., p. 49.

Tetranychopsis simplex Trägårdh, 1904, Zool. Exp. Egypt and the White Nile 1901, 20(1):

8. New synonymy.

Tetranychus longipes Banks, 1912, Ent. Soc. Wash. Proc. 14: 97.

Tetranobia decepta Banks, 1917, Ent. News 28: 194.

Tetranychina tritici Ewing, 1921, U. S. Natl. Mus. Proc. 59(2394): 665.

Petrobia cephae Sayed, 1946, Soc. Fouad 1 ${ }^{\text {er }}$ Ent. Bul. 30: 79. New synonymy. 


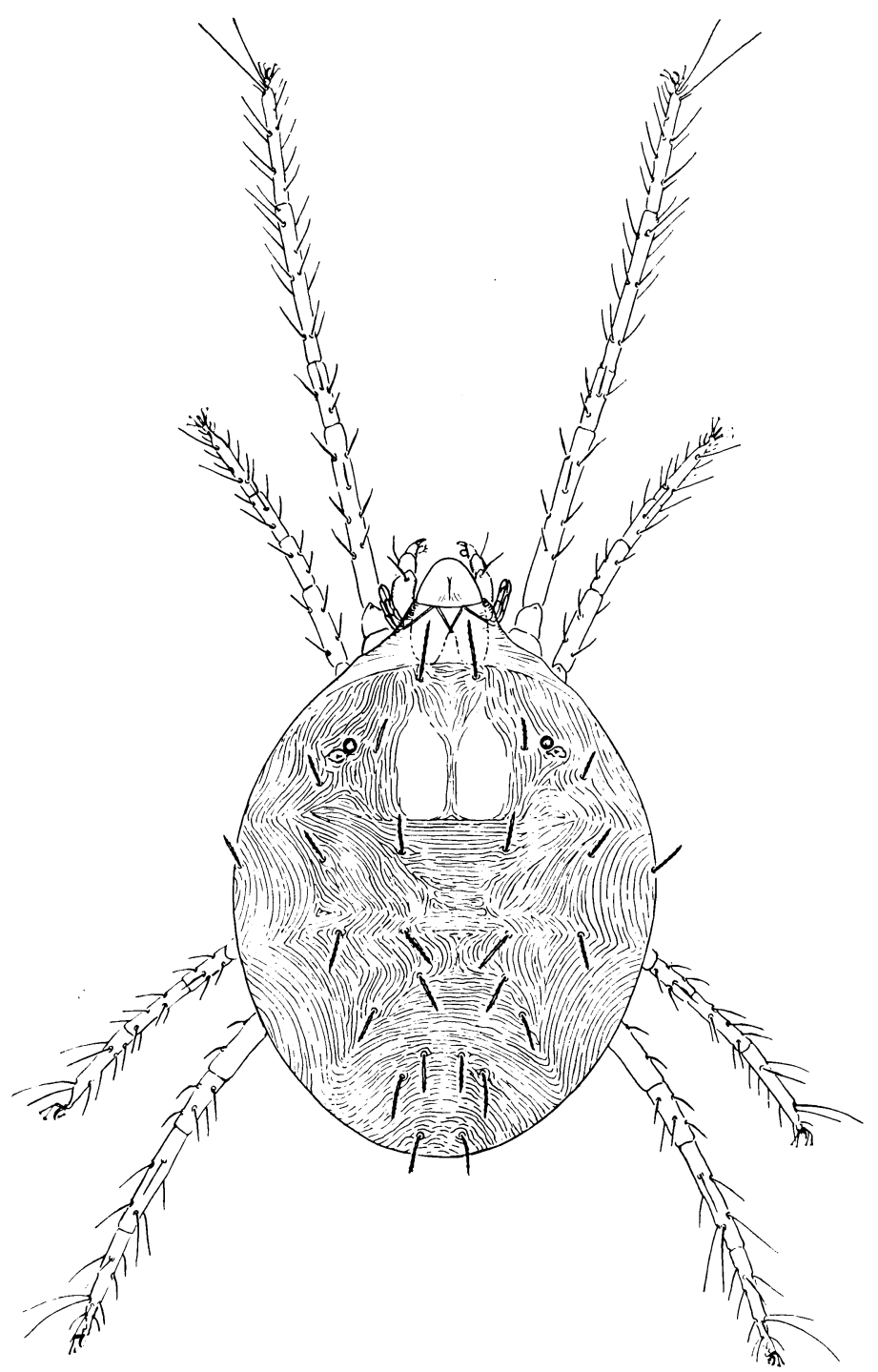

Fig. 3. Petrobia latens: female.

Identification. The clawlike empodium (fig. 2) bearing two rows of ventrally directed, knobbed hairs will serve to differentiate this species from others that may be found on cotton.

Field Recognition. The rotund, metallic dark brown or metallic greenish body with very short dorsal setae (fig. 3) will serve for hand-lens identification in the field. The legs are pale yellowish, and the fore legs of the female are characteristically elongate. 
Biological Notes. Petrobia latens flourishes in the western United States on grasses during the period of winter rains. It may invade young fields of cotton in the spring. Damage to cotton, however, is not considered serious because of the sporadic attacks of this mite and its disappearance with hot and dry weather. However, Fenton (1951) reports that Petrobia latens is strictly a dry-weather pest of wheat in Oklahoma, and that its damage to wheat is similar to that caused by drought. Fenton states that the mite disappears with rain in that area.

As observed by Fenton and earlier workers, two types of eggs are laid, no female producing both types. The egg of the actively reproducing stage is red and spherical, with radial striations and a small stipe dorsally. The egg

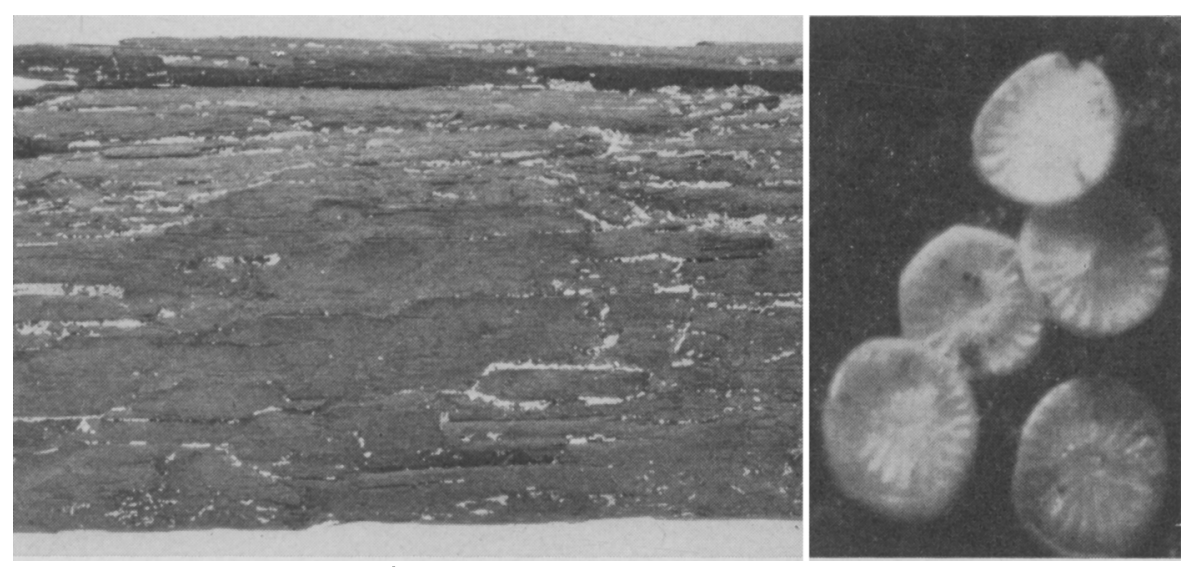

Fig. 4. Petrobia latens: dormant eggs on piece of wood, with enlargement of five eggs.

serving for dormancy-overwintering in Oklahoma but estivating in California-is coated with a white material bearing a circular, radially striated cap (fig. 4).

Fenton found that the active eggs hatch in about 1 week at $75^{\circ} \mathrm{F}$. Under similar conditions the newly hatched larvae develop to adults in 8 or 9 days. Females begin oviposition in 1 or 2 days and lay from 70 to 90 active eggs or 30 dormant eggs over a period of 3 weeks.

This species is entirely parthenogenetic, males being unknown.

Occasionally Petrobia latens invades homes.

Distribution. Petrobia latens is almost world-wide in distribution, being known to occur in Europe, North Africa, North America, and Australia. It is known from scattered localities throughout the United States but reaches most noticeable abundance in the southwestern and western states.

Hosts. Petrobia latens is particularly a pest of low-growing monocotyledonous plants. It occurs on grains such as barley, wheat, rye, and sorghum; many kinds of grasses ; onions and garlic ; iris and gladioli. Reynolds, Anderson, and Swift (1952) report damage to carrots. Other recorded hosts include alfalfa, bur clover, and cotton. Specimens have also been received from cantaloupes, melons, and lettuce. 


\section{GENUS PARATETRANYCHUS ZACHER}

Paratetranychus Zacher, 1913, Kais. Biol. Anst. f. Land- und Forst. Mitt. 14: 39. Type of genus, Tetranychus ununguis Jacobi; by subsequent designation of Trägårdh, 1915.

The genus Paratetranychus contains a large number of species that are almost invariably found on perennial grasses or perennial trees and shrubs.

Zacher (1920) described Paratetranychus gossypii and reported it to be a pest of cotton in Africa. Hirst (1926) recorded this species from beans, as well as Cassava and Carica. The aedeagus of this species is distinctive (fig. 5).

Ugarov and Nikolskii (1937) deseribed Paratetranychus stenoperitrematus $^{4}$ from cotton in middle Asia. Other hosts include watermelon, corn, and thistle. The description of the aedeagus is similar to those of the grass-

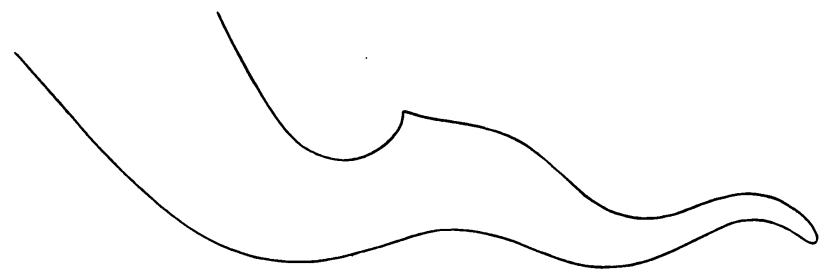

Fig. 5. Paratetranychus gossypii: aedeagus (after Hirst, 1926).

infesting species of Paratetranychus, and the occurrence of this species on cotton is probably incidental.

Paratetranychus peruvianus McGregor $(1917 a)^{5}$ has been reported from cotton in Peru. This mite is also recorded from Trinidad and southern California but is not known to occur on cotton in these areas. Additional hosts include grapes, willow, and carob. This species may be differentiated from other members of the genus Paratetranychus that are known from cotton by having the dorsal setae of the body obviously shorter than the intervals between them. Very restricted colonies are formed.

A species closely related to Paratetranychus gossypii has been found on cotton in Central America. Its description follows.

\section{Paratetranychus mcgregori, new species McGregor Spider Mite \\ (Figs. 6, 7, 8)}

Paratetranychus megregori may be differentiated from all other members of the genus by having the two pairs of duplex setae on tarsus I widely separated and placed medially on the segment (nearly as in Tetranychus), and by having the peritreme strongly hooked distally (as in most species of Tetranychus). The aedeagus is similar to the distinctive type represented by $P$. gossypii, but the distal end is drawn out to a very long and slender stylet.

Female. Palpus with terminal sensillum slender, over twice as long as wide. Stylophore somewhat emarginate mediodistally. Tibia I (fig. 6) with

- New combination; originally described as Eotetranychus stenoperitrematus Ugarov and Nikolskii.

s Paratetranychus trinitatis Hirst (1922) is a new synonym. 

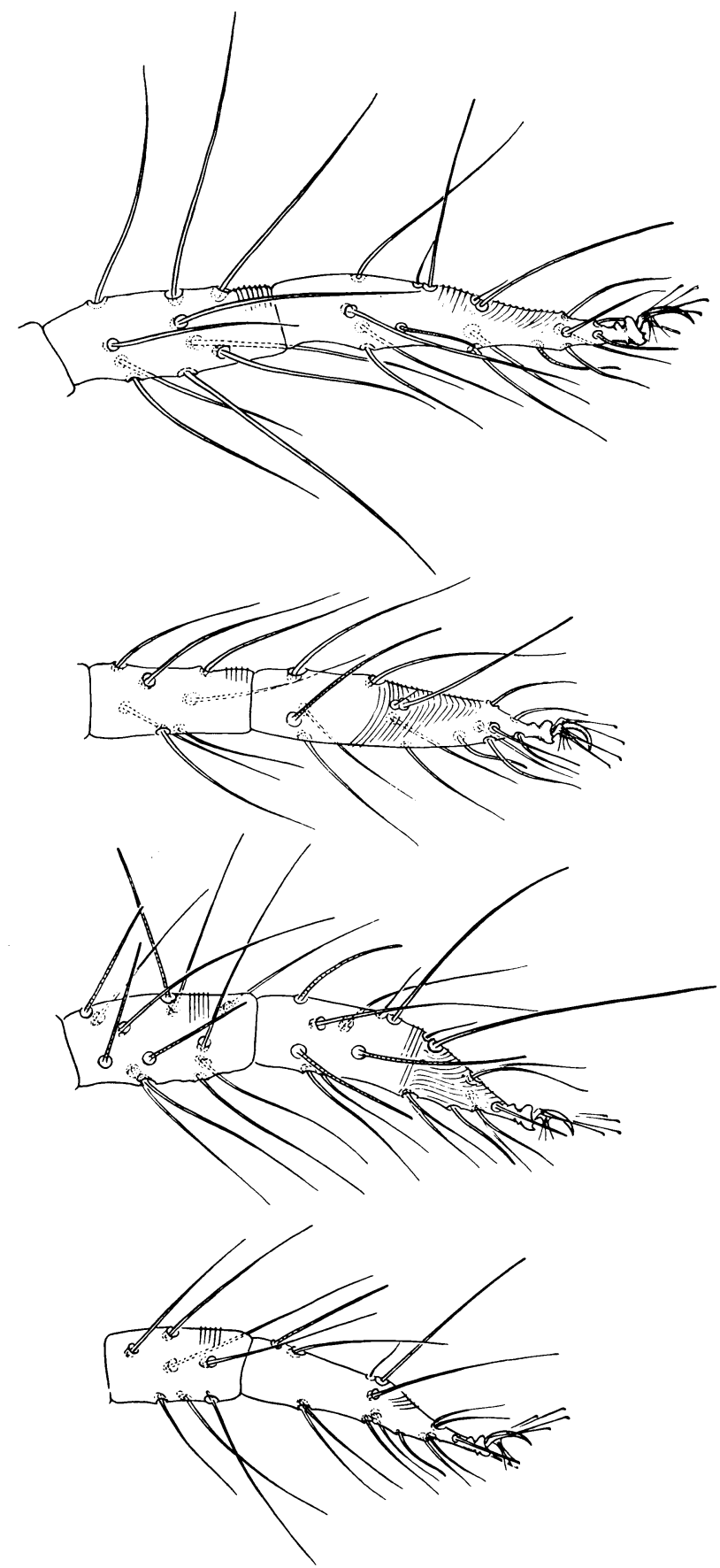

Fig. 6. Paratetranychus megregori: from top to bottom, tibia and tarsus I of female; tibia and tarsus II of female; tibia and tarsus I of male; tibia and tarsus II of male. 


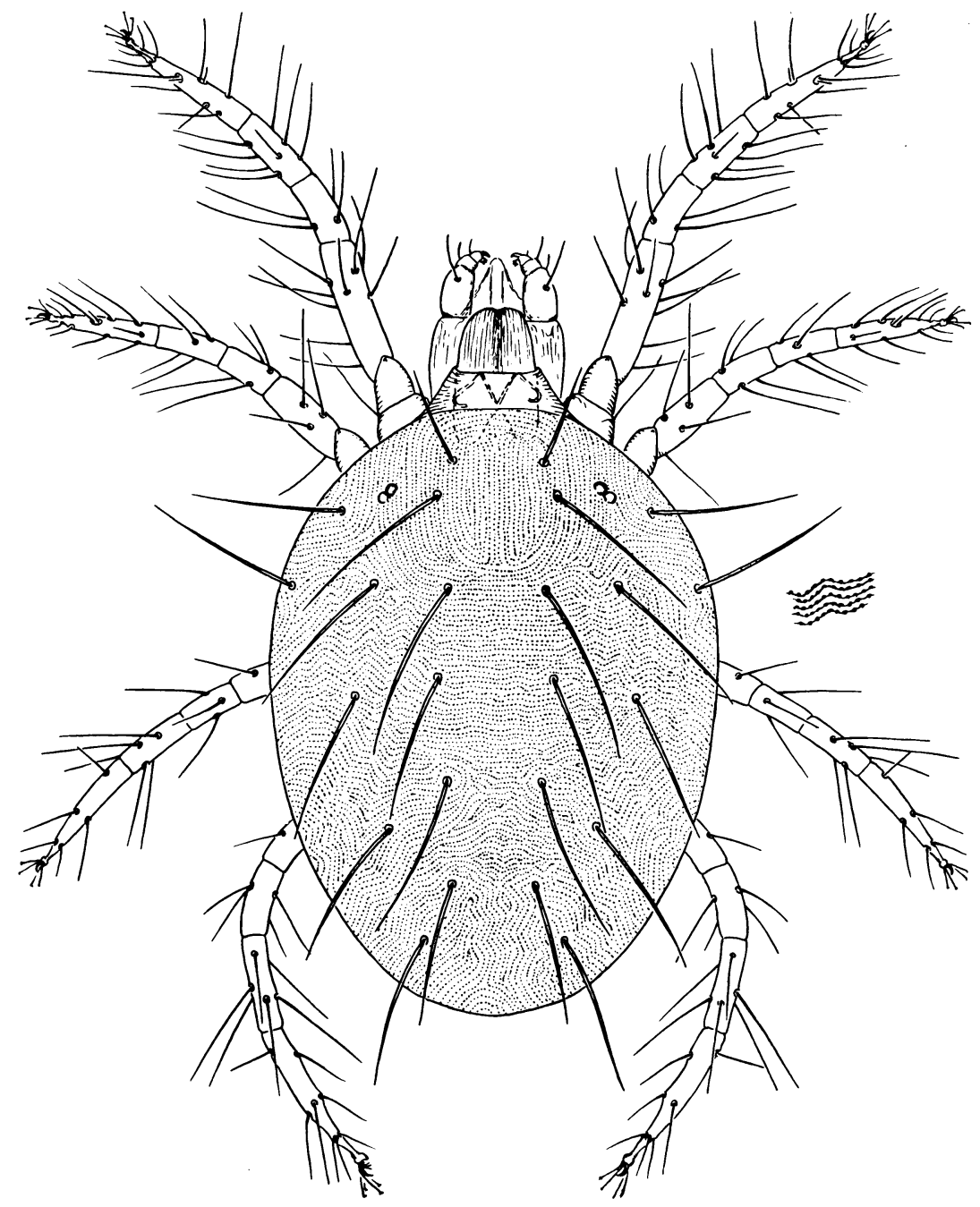

Fig. 7. Paratetranychus mcgregori: female.

nine tactile setae and a mediolateral sensory seta; tarsus I long and slender, gradually narrowed, the duplex setae well separated and medially placed, with one sensory and four tactile setae proximad of duplex setae; empodial claw (fig. 8) slender and roundly curved, with three pairs of proximoventral setae that are about as long as the claw. Tibia II (fig. 6) with seven tactile setae; tibiae III and IV also without sensory setae. Dorsum of body (fig. 7) with striae composed of short dashes, mostly transverse; dorsal setae slender and tapering, much longer than intervals between bases, very finely pubescent, and not set on tubercles. Length of body $466 \mu$; including rostrum $560 \mu$.

Male. Similar to female except tibia I (fig. 6) with nine tactile and four (or three) sensory setae, and tarsus I with four tactile and two sensory setae. 
Aedeagus (fig. 8) with proximal portion of external shaft curved dorsad and strongly narrowing, with a small dorsal angulation at proximal third and extending beyond this as an extremely narrow style (a broader peripheral line, widely separated under the stylus, appears as a membranous sheath; if it represents the true aedeagus, the style represents the seminal duct). Length of body $247 \mu$; including rostrum $313 \mu$.

Holotype. Male, Chinandega, Nicaragua, February 11, 1952 (Swain), on cotton; type no. 2063 in the U. S. National Museum.

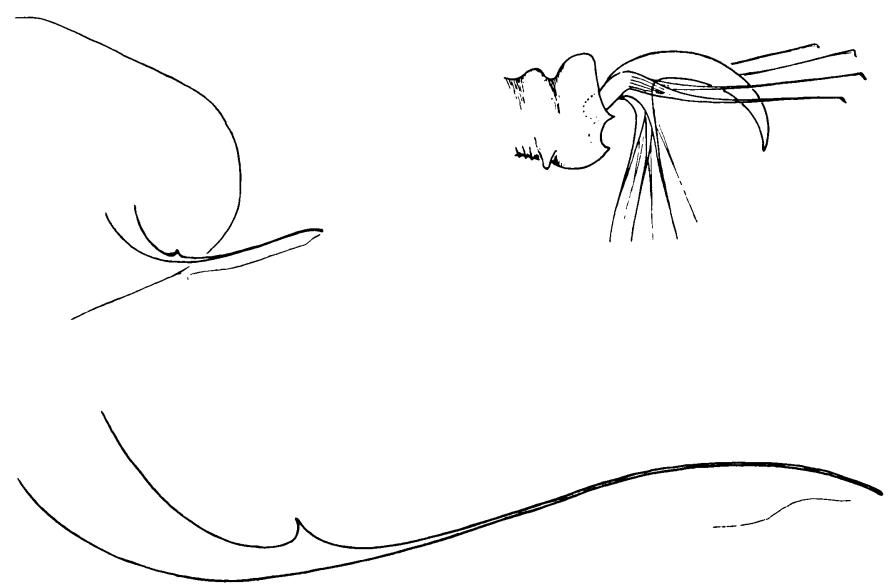

Fig. 8. Paratetranychus megregori: aedeagus and empodial appendages of tarsus II of female.

Paratypes. One male, nine females, Managua, Nicaragua, December 20, 1951 (E. Pinell), on cotton ; three females, Chinandega, Nicaragua, January 12, 1952 (Swain), on cotton ; one male, Chinandega, Nicaragua, February 11, 1952 (Swain), on cotton.

This species is named in honor of E. A. McGregor, who has made many significant contributions to the taxonomy of cotton spider mites.

\section{GENUS TETRANYCHUS DUFOUR}

Tetranychus Dufour, 1832, Sei. Nat. Paris Ann. 25: 276. Type of genus, Tetranychus lintearius Dufour; monobasic.

Distigmatus Donnadieu, 1876, Ann. Soc. Linn. Lyon (1875) 22: 146. Type of genus, Distigmatus pilosus Donnadieu; monobasic.

Epitetranychus Zacher, 1916, Kais. Biol. Anst. f. Land- und Forst. Mitt. 16: 22. Type of genus Tetranychus altheae; by original designation.

Septanychus MeGregor, 1919, U. S. Natl. Mus. Proc. 56(2303): 663. Type of genus, Tetranychus tumidus Banks; by present designation. New synonymy.

All the mites that are major pests of cotton belong to the genus Tetranychus. A number of species are included in the genus, and many are important pests of agriculture.

The presence of a small but obvious mediodorsal spur on each of the empodia was considered by McGregor (1919) to be a character worthy of generic 
value, and he proposed the generic name Septanychus for species exhibiting this character. McGregor (1950) later included in Septanychus those species in which a rudimentary empodial spur was detected. The rudimentary empodial spur has been observed in all species of Tetranychus studied by us, and we do not consider the comparative development of the empodial spur in this particular instance to be worthy of generic consideration. Septanychus is therefore regarded as a synonym of Tetranychus.

The genus Tetranychus may be divided into several species groups according to the pattern of the dorsal striae between the inner lumbar and inner sacral setae of the females, the placement of the proximal duplex setae, and the development of the dorsal spur of the empodium. Otherwise, species identification is dependent entirely on the configuration of the aedeagus as seen laterally.

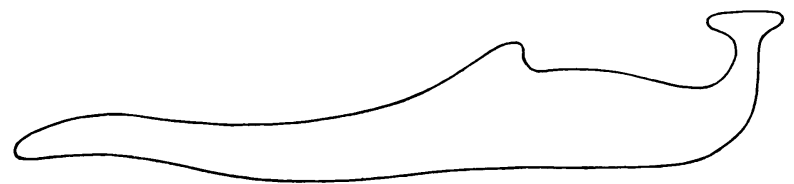

Fig. 9. Tetranychus turkestani: aedeagus (after Ugarov and Nikolskii, 1937).

The shape of the aedeagus is not entirely constant, and a knowledge of its variation, particularly with reference to the apparent variation due to inaccurate orientation, is necessary for critical taxonomic study of the species.

Nevertheless, it is believed that the entomologist working with the cotton fauna of a given area can make routine identifications as accurate as those of the taxonomic specialist.

In addition to the species included in the following key to American mites known from cotton, there are three species that receive no further consideration.

One of these is Tetranychus turkestani Ugarov and Nikolskii (1937). This species is reported to be the common pest of cotton in the middle-Asiatic region. Although the original description obviously refers to a species very similar to the two-spotted spider mite on cotton in the southern United States and in the Mediterranean region, the enlargement of the distal end of the aedeagus, as figured by the original authors (fig. 9), is different from other known species.

Another species is Tetranychus neocaledonicus André (1933). This species was described as a pest of cotton in New Caledonia, but Mons. F. Cohic informs us that cotton is no longer a commercial crop on the island. The original description was based on females only, and the species is probably close to or identical with $T$. marianae McGregor, a species that is common and widespread in the Pacific region.

The third species is Tetranychus bioculatus Wood-Mason, which was reported by Hargreaves (1948) as infesting cotton in Nyasaland. T. bioculatus was described from tea in Ceylon and it properly belongs to the genus Paratetranychus. The mite from Nyasaland is possibly a true Tetranychus and perhaps bimaculatus. 


\section{Key to Species of Tetranychus Known from Cotton in North and Central America ${ }^{b}$}

1. Female with transverse integumentary striae between the inner lumbar setae (fig. 10) 2

-. Female with longitudinal striae between the inner lumbar setae (fig. 16) . . . . . . 4

2. Female with longitudinal striae between the inner sacral setae (fig. 13); aedeagus with anterior projection of distal knob rounded or broadly angulate (fig. 14) . . . . . . 3

-. Female with transverse striae between the inner sacral setae (fig. 10); aedeagus with anterior projection of distal knob sharply angulate (fig. 12) ............ pacificus

3. Aedeagus with distal knob strongly enlarged, about one half as long as external portion

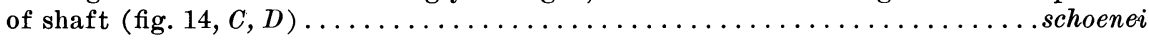

-. Aedeagus with distal knob much smaller, about one fourth as long as external portion

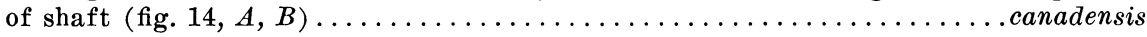

4. Tarsus I with proximal duplex setae approximately in line with other proximal setae

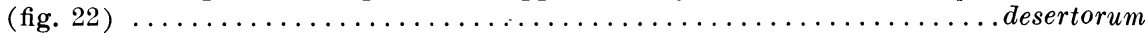

-. Tarsus I with proximal duplex setae distad of other proximal setae (fig. 17, $A$ ) .... 5

5. Tarsus (excluding tarsi I and II of male) with an obvious empodial spur (fig. 23)

tumidus

-. Tarsus (excluding tarsi I and II of male) with the empodial spur rudimentary

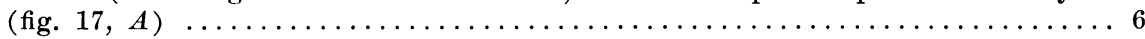

6. Aedeagus with distal knob comparatively large, slightly less than one third as long as

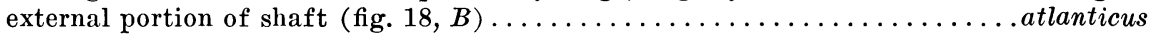

-. Aedeagus with distal knob very small, not over one sixth as long as external portion

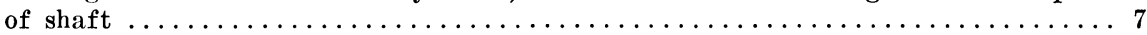

7. Aedeagus with caudal angulation of distal knob slender and directed more or less dorsad, distinctly longer than the anterior angulation (fig. 20) ..............marianae

-. Aedeagus with eaudal angulation small and directed caudad, similar in size to the an-

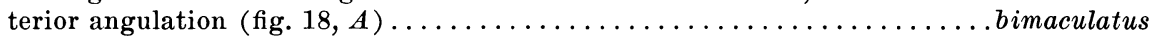

\section{Field Guide to Species of Tetranychus Known from Cotton in North and Central America ${ }^{7}$}

1. Adult female principally green, yellowish green, or straw-colored........... 2 -. Adult female carmine (plate $1, B$ ) ......tumidus, bimaculatus, desertorum, marianae

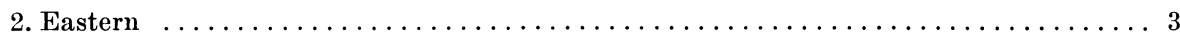

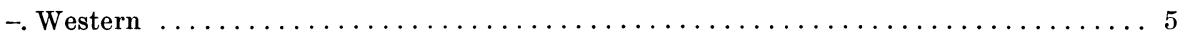

3. Adult female with separate dark spots at caudal end of body......schoenei, canadensis

-. Adult female without separated dark spots at caudal end of body ........... 4

4. Feeding in restricted colonies, soon causing bright-red blotches on leaves, and inducing

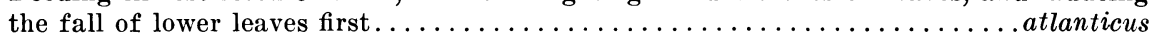

-. Feeding in colonies between large veins and not causing leaf drop........bimaculatus

5. Adult female with separate dark spots at caudal end of dorsum; mites spreading rapidly over entire leaf and not colonizing; feeding injury and copious webs giving leaves grayish appearance far in advance of reddening...................... pacificus

-. Adult female without separate dark spots caudally on dorsum; mites colonizing.... 6

6. Feeding in restricted colonies, soon causing bright-red blotches on leaves, and inducing

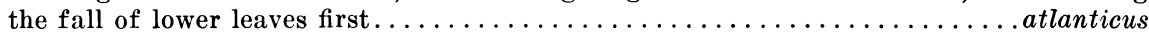

-. Feeding in colonies between large veins and not causing leaf drop........ bimaculatus

${ }^{6}$ Males may be identified by referring to figures of the aedeagus when females are not available and definitely associated.

7 This key is based on a number of actively feeding adult females under average conditions. Teneral (immature) females and heavily feeding females are atypical. Nonfeeding females become orange (plate $1, C$ ). 


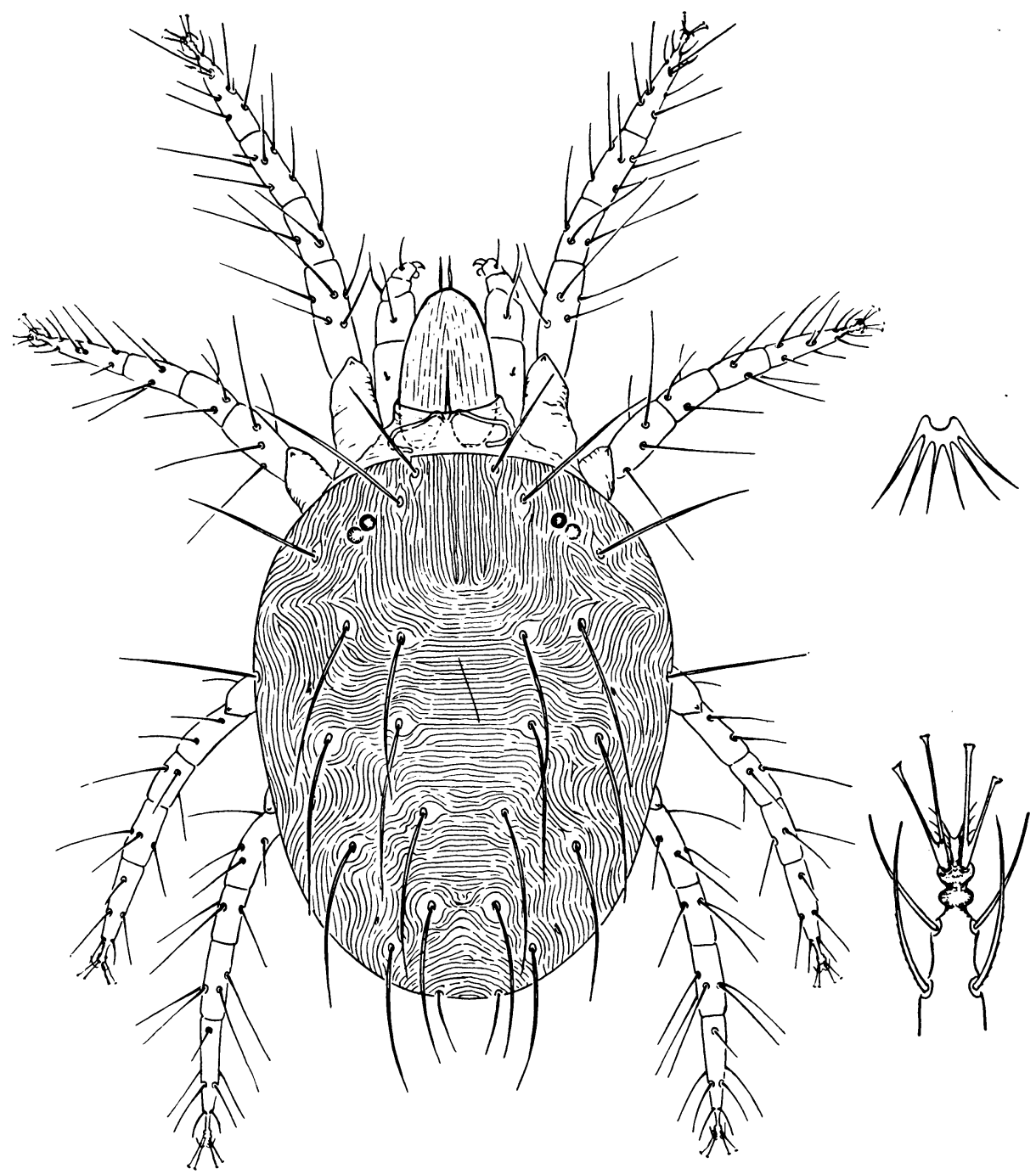

Fig. 10. Tetranychus pacificus: female showing dorsal striae, with enlargement of ventral aspect of empodium and dorsal aspect of tarsal appendages.

\section{Tetranychus pacificus McGregor Pacific Spider Mite}

(Figs. 10, 11, 12)

Tetranychus pacificus McGregor, 1919, U. S. Natl. Mus. Proc. 56(2303) : 657.

Identification. The female may be distinguished from all other species of Tetranychus on cotton by the presence of transverse striae between both the inner lumbar and inner sacral setae (fig. 10). The aedeagus (fig. 12) is distinctive in that the distal knob has an acute angulation anteriorly and a long, tapering angulation posteriorly. 


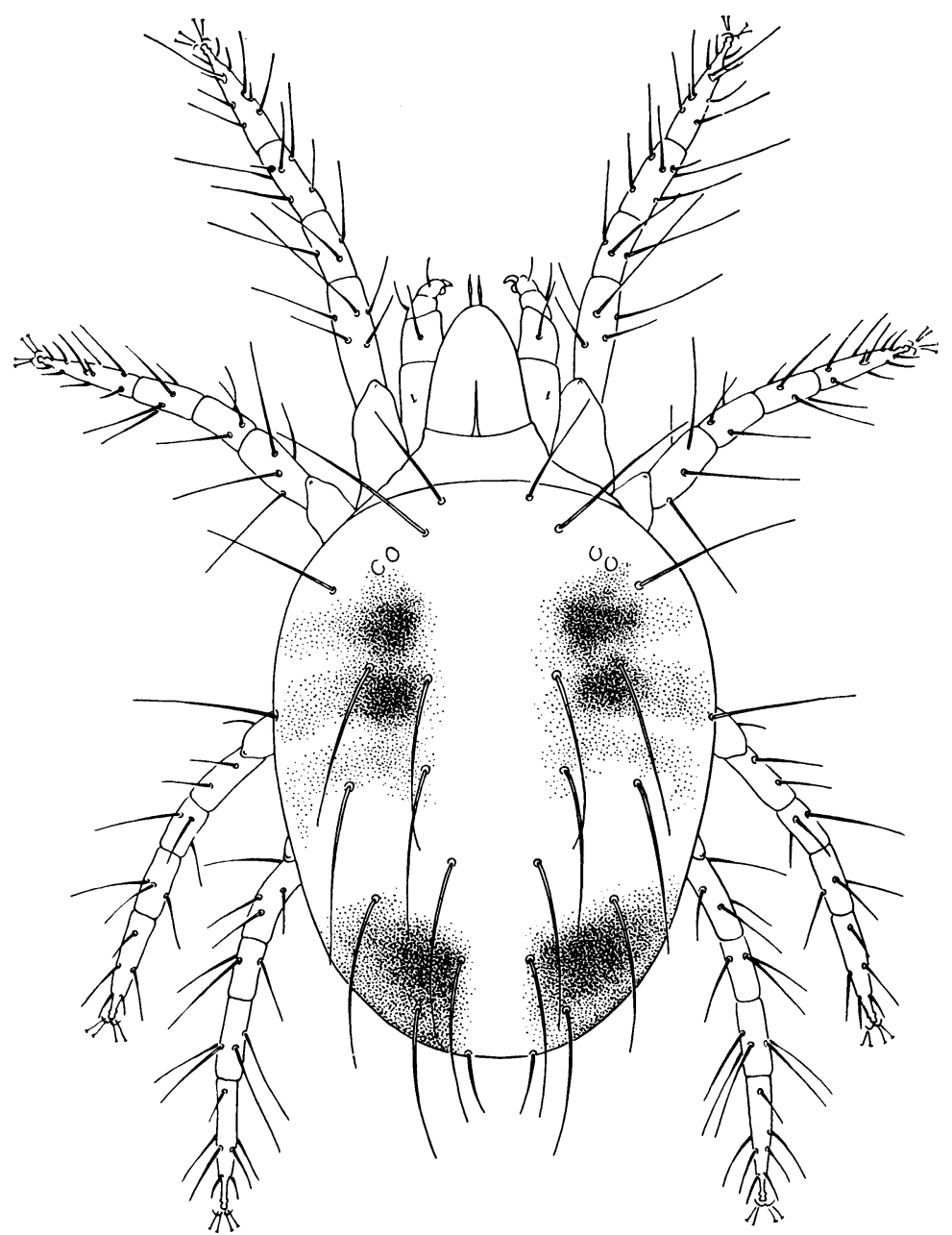

Fig. 11. Tetranychus pacificus: female showing markings when feeding.

Field Recognition. Actively feeding females are greenish in color, with dark spots medially and a pair of dark spots at the posterior end of the body (fig. 11). They scatter evenly over the leaves to feed and spin copious webbing. This species is known only from the Pacific Coast.

Biological Notes. Overwintering females are bright orange, but the greenish, actively feeding females have been found on winter covercrops and weeds in California cotton fields. Ordinarily the cotton infestation is late in the summer, presumably from infestations building up on alfalfa and weeds.

Gordon L. Smith reports that Tetranychus pacificus was first recognized on cotton in California in 1947, but this species has subsequently become a dominant pest.

Hosts. Tetranychus pacificus is a serious pest of cotton and deciduous fruits in California. Alfalfa, clover, vetch, melons, beans, grapes, and berries 

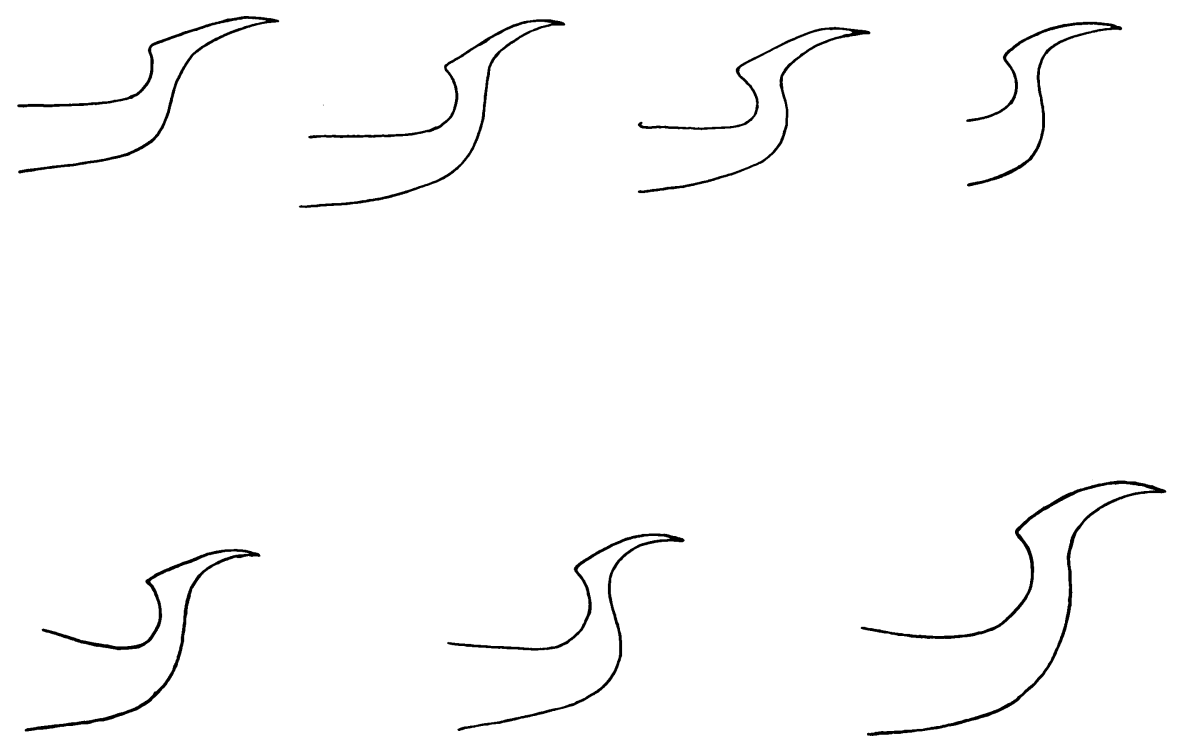

Fig. 12. Tetranychus pacificus: aedeagi.

are favorite hosts. Weeds such as sunflower, tarweed, morning glory, California poppy, milkweed, salvia, and pigweed are good hosts. Black locust, elm, ceanothus, garrya, cotoneaster, and mountain mahogany also maintain populations.

Distribution. The Pacific spider mite occurs from British Columbia to California. It is abundant in the San Joaquin Valley of California where cotton is grown. No specimens have been received from Arizona.

\section{Tetranychus schoenei McGregor Schoene Spider Mite}

(Figs. 13, 14, C, D)

Tetranychus schoenei MeGregor, 1941, Ent. Soc. Wash. Proc. 43: 223.

Identification. Females of Tetranychus schoenei resemble those of $T$. canadensis and $T$. pacificus in that the integumentary striae are transversely parallel between the inner lumbar setae. However, the striae are longitudinal between the inner sacral setae, as in $T$. canadensis, thus differing from $T$. pacificus (fig. 13). No characters are known to separate females of $T$. schoenei and T. canadensis, and males must be mounted for accurate determination.

The aedeagus ends in a large terminal knob, its width being about one half as long as the external shaft (fig. 14, $C, D$ ). This character will distinguish this species from Tetranychus canadensis.

Field Recognition. Tetranychus schoenei closely resembles T. canadensis, with which it may be associated in the field. The females of both species are characterized by being greenish with dark, paired spots on the body medially and at the posterior end. Considerable webbing is spun. 


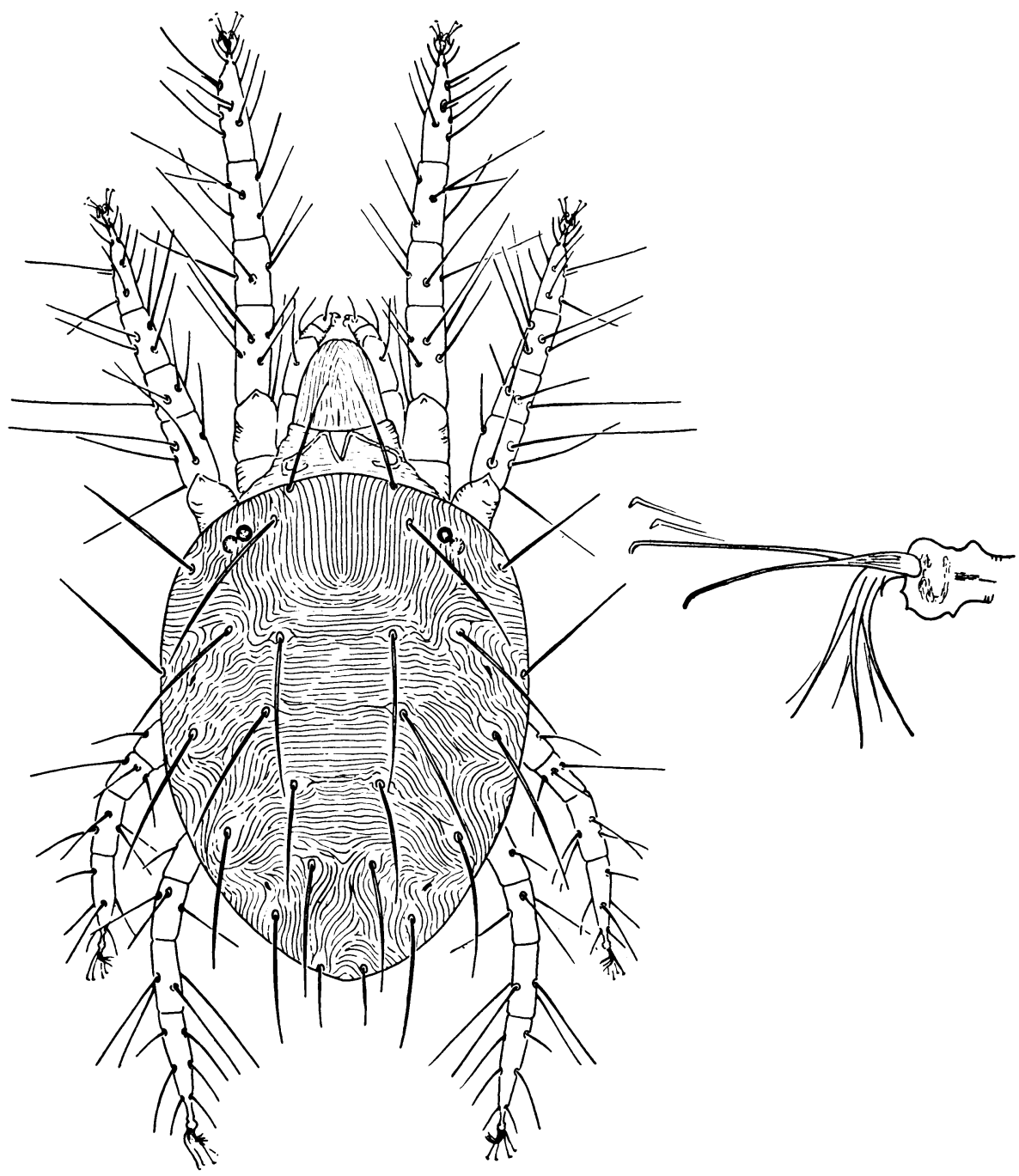

Fig. 13. Tetranychus schoenei: female showing dorsal striae, with enlargement of tarsal appendages.

Biological Notes. Cagle (1943) has made the only biological study of this species. The females overwinter as bright-orange adults. Nine generations were found to occur annually in Virginia, with some females on deciduous fruit trees going into hibernation during the sixth generation.

The preoviposition period of actively feeding females lasts several days, and a single female laid as many as 106 eggs at a maximum rate of $3.7 \mathrm{eggs}$ per day. The incubation period ranged from 3 days at an average of $81.6^{\circ} \mathrm{F}$ to 25 days at an average of $52.6^{\circ}$.

Development from the newly hatched larva to adult was 5 days at $80.7^{\circ}$ $\mathrm{F}$, but it was protracted to 34 days at $51^{\circ}$. 

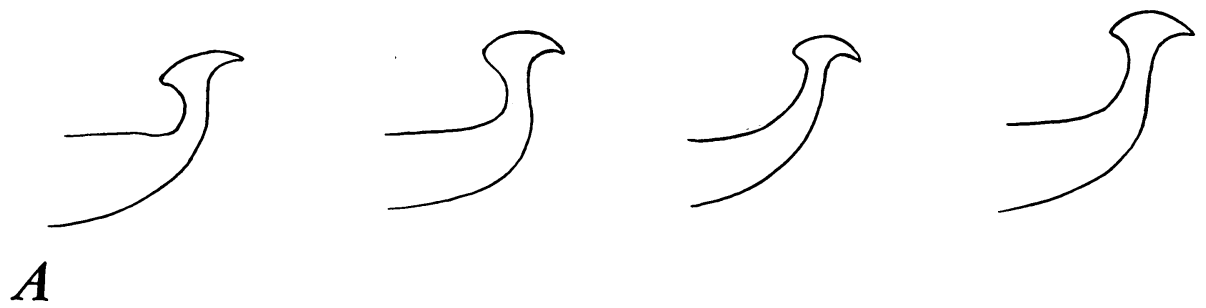

$A$
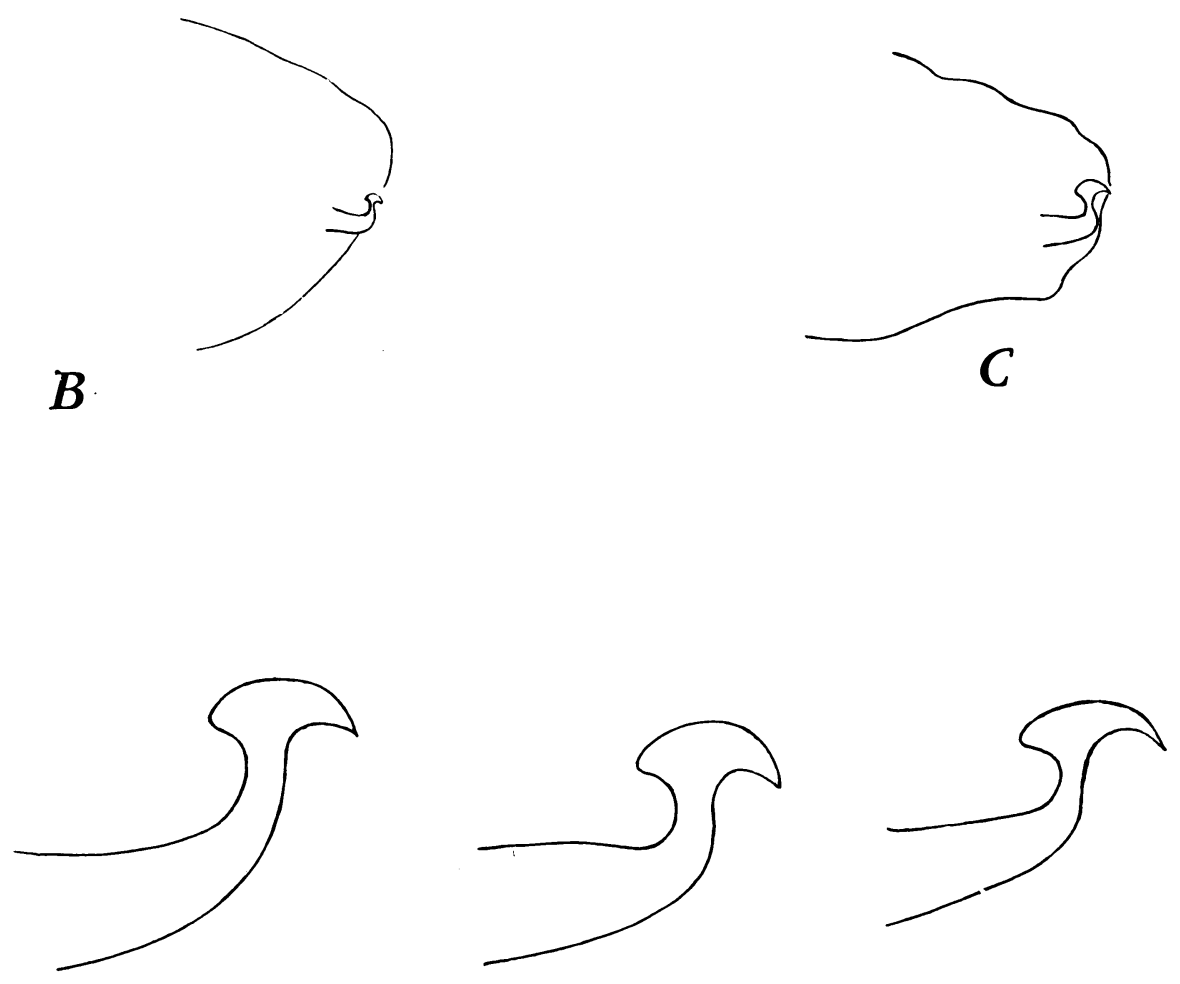

\section{$D$}

Fig. 14. Aedeagi: $A, B$, of Tetranychus canadensis; $C, D$, of $T$. schoenei. The entire cauda $-B$ and $C-$ are drawn to the same scale.

Hosts. Tetranychus schoenei is found on deciduous fruit and ornamental trees, as well as field crops. Apple, black locust, cotton, beans, and brambles are known to be hosts.

Distribution. This species is known to occur in Maryland, Virginia, West Virginia, Pennsylvania, Louisiana, Mississippi, Alabama, and Georgia. 

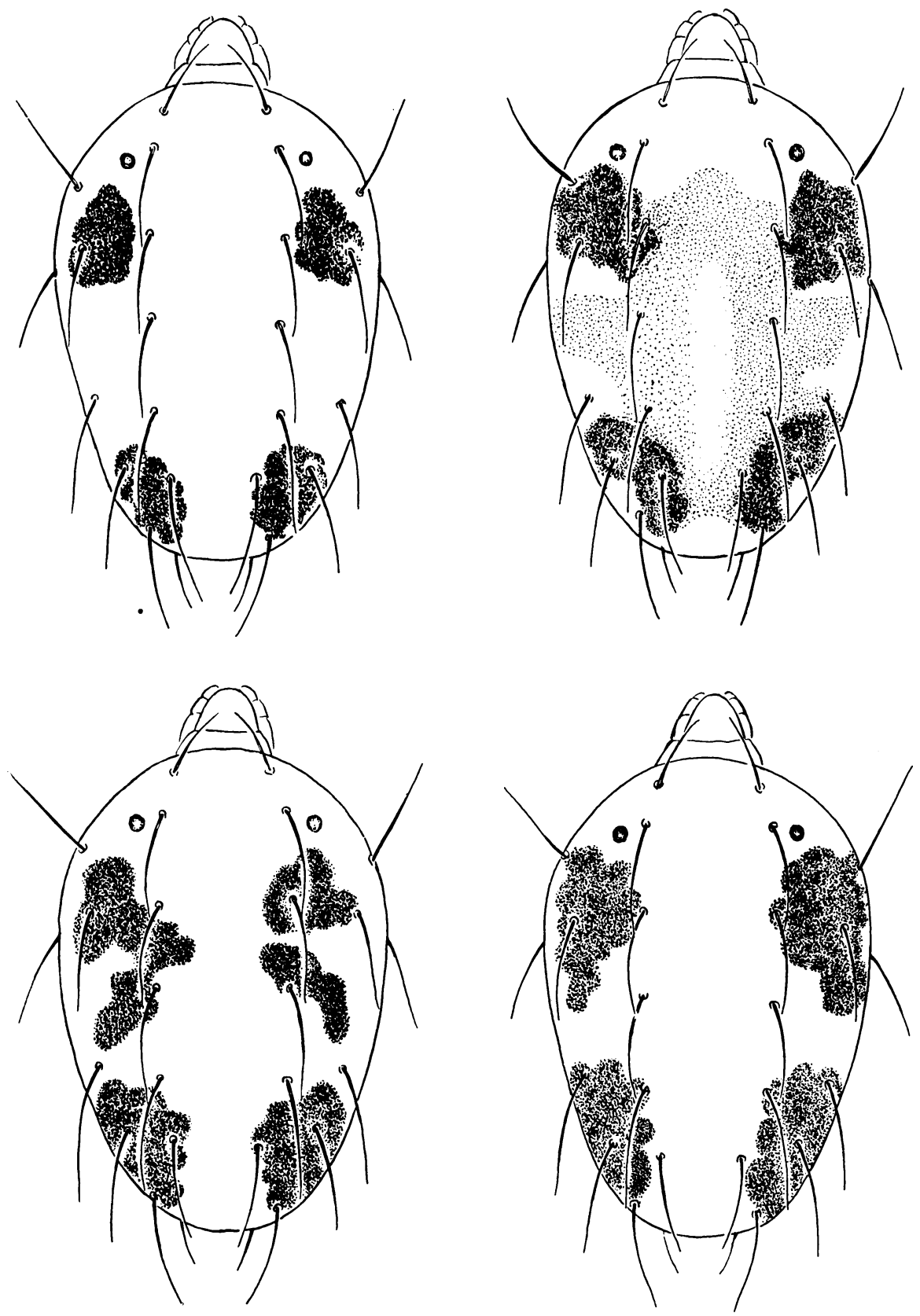

Fig. 15. Tetranychus canadensis: females showing markings when feeding. 


\section{Tetranychus canadensis (McGregor) Four-spotted Spider Mite \\ (Figs. 14, $A, B, 15$ )}

Septanychus canadensis MeGregor, 1950, Amer. Midland Nat. 44: 319.

Identification. Females of Tetranychus canadensis resemble those of $T$. schoenei and T. pacificus in that transverse integumentary striae are found between the inner lumbar setae, but the striae are longitudinal between the inner sacral setae as found otherwise only in T. schoenei.

The species may be differentiated from Tetranychus schoenei in that the distal knob of the aedeagus is comparatively small, less than one fourth as long as the external shaft (fig. 14, $A, B$ ).

Field Identification. Adult females in colonies of Tetranychus canadensis resemble those of $T$. schoenei in that both "shoulder spots" and "tail spots" are present (fig. 15). Males must be mounted to differentiate the two species.

Biological Notes. Lienk and Chapman (1951) have made preliminary observations on the biology of this species. Their studies were made with regard to the behavior of the mite on fruit trees in New York.

Hosts. The type host was apple. Other specimens studied were collected on cotton, rose, elm, linden, plum, horse chestnut, and Osage orange.

Distribution. Tetranychus canadensis was originally recognized from Ontario, Canada. Subsequently this species has been found from seattered localities in the eastern and midwestern United States: New York, New Jersey, Washington, D.C., Maryland, Virginia, Indiana, Ohio, Kansas, Texas, Louisiana, Mississippi, and Tennessee.

\section{Tetranychus bimaculatus Harvey Two-spotted Spider Mite \\ (Plate 1, figs. 16, 17, 18, $A$ )}

Tetranychus bimaculatus Harvey, 1893, Maine Agr. Exp. Sta. Ann. Rep. 1892: 133.

Nomenclatural Status. The scientific name of the two-spotted spider mite, as employed here, is admittedly provisional. This species is also common in Europe where a number of scientific names have priority.

Acarus telarius Linnaeus, 1758, was the first name proposed for this mite, but Linnaeus unfortunately included another species in his description. Acarologists have subsequently been in disagreement as to which species the name should apply, and there are very good arguments for both viewpoints.

Acarus sambuci Schrank, 1781, is a name that appears to be applicable to the two-spotted spider mite, if Acarus telarius is not accepted. European workers have not definitely established that the name sambuci pertains to this species, although Oudemans (1930) and Geijskes (1939) regard the name as being applicable to the two-spotted spider mite complex.

Acarus textor Fourcroy, 1785, was proposed for mites collected in England, and Fourcroy's description obviously refers to the common spinning mite of Europe, or the two-spotted spider mite.

The genus Tetranychus Dufour, 1832, was based on a new species, T. lintearius. His description obviously refers to the common spinning mite of 


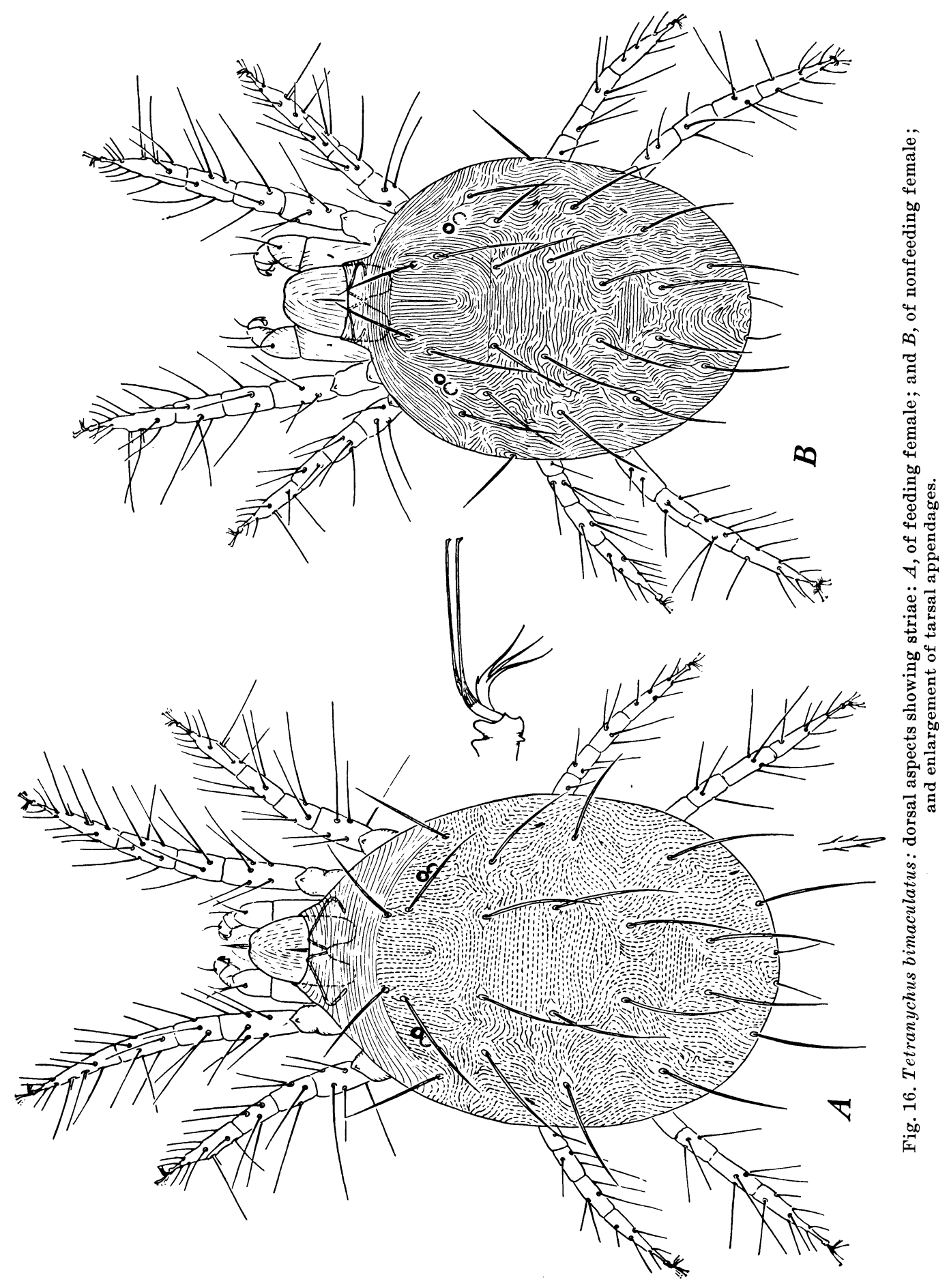



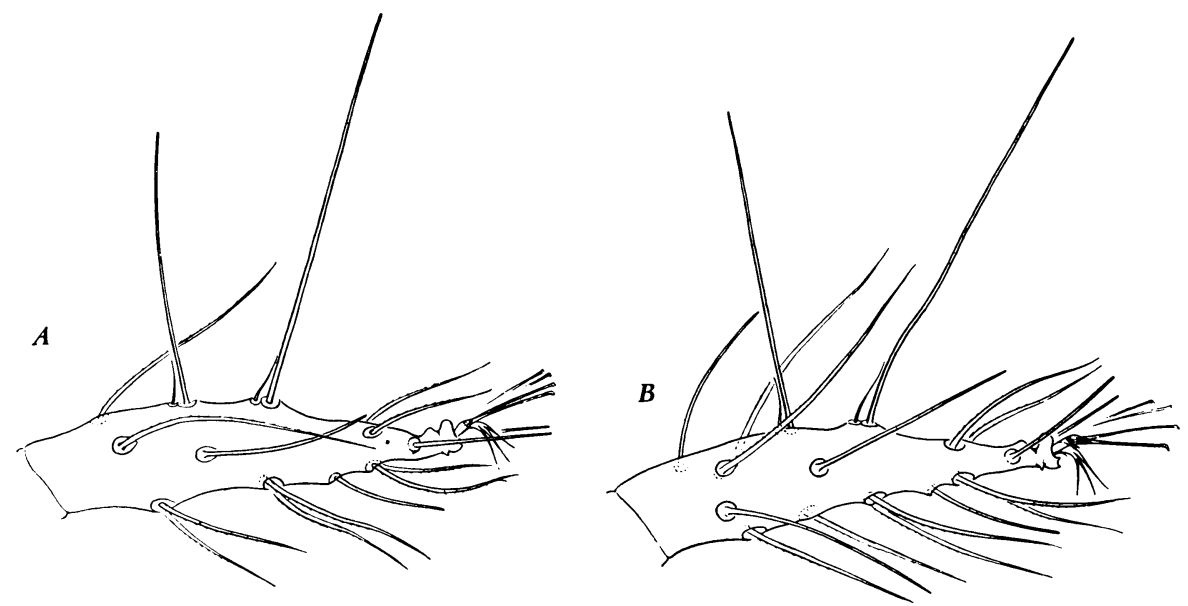

Fig. 17. Tetranychus bimaculatus: tarsus I of female showing: A, typical bimaculatus and $B$, “multisetis" type of chaetotaxy.

Europe, or the two-spotted spider mite. Two collections of topotype material studied by us bear out this conclusion.

There is no doubt that one of these or many other earlier names appropriately precedes Tetranychus bimaculatus as a scientific name for the twospotted spider mite. Our studies have not substantiated the opinion of McGregor (1950) that the North American species is distinct from the similar species in Europe or that there are two species involved (McGregor, 1942).

Tetranychus urticae Koch, 1836, and T. altheae von Hanstein, 1901, are names in current use in Europe.

The acceptance of an appropriate scientific name for this mite must be determined by acarologists in the future, particularly after a modern survey of the occurrence of species belonging to the genus Tetranychus in Europe.

Identification. The female of Tetranychus bimaculatus resembles several other species in that the integumentary striae are longitudinal between the inner sacral and inner lumbar setae, and a diamond-shaped figure is formed in the area between these setae (fig. 16).T. bimaculatus, as well as T. atlanticus and T. marianae, differs from other species on cotton with such striae by having the duplex setae distad of the other proximal setae on tarsus I and the empodial claw rudimentary (fig. 17). Females of these three species are indistinguishable, and the aedeagus of the male must be relied upon for identification.

The aedeagus of the male (fig. 18, $A$ ) has an extremely small and nearly evenly shaped distal knob; this will serve for recognition of the species.

Biological Notes. There have been many biological studies of the twospotted spider mite. Ewing (1914), McGregor and McDonough (1917), and Cagle (1949) are among the most thorough investigators in the United States, and Gasser (1951) is one of the most recent workers in Europe. 


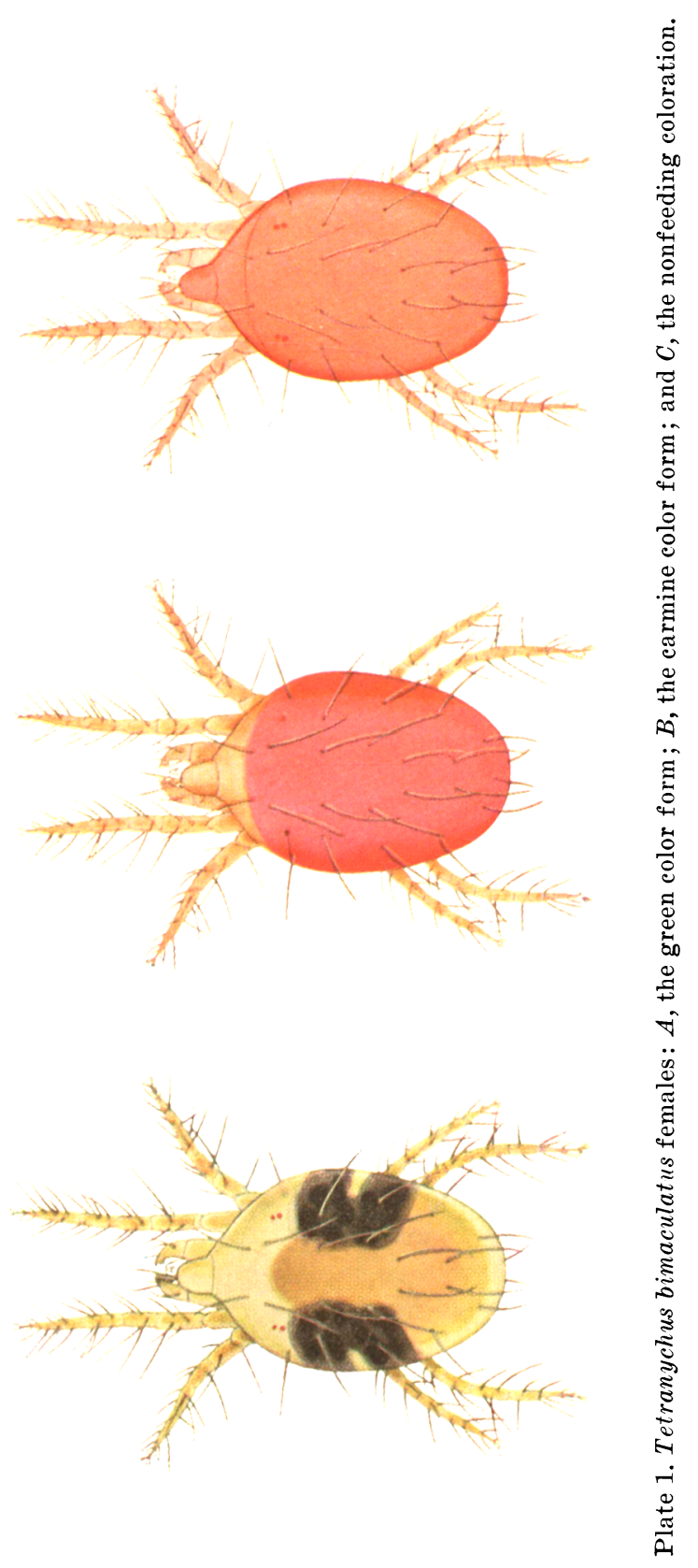


Tetranychus bimaculatus will often overwinter on weeds, continuing reproduction when temperatures are favorable, but hibernating colonies of orange females are sometimes found in orchards.

Color Forms. There are two basic color forms of actively feeding females of Tetranychus bimaculatus: Carmine and green. Nonfeeding females of both forms become orange (plate $1, C$ ). Each is worthy of subspecific rank.

The actively feeding females that are found in a more subtropical distribution are often carmine (plate 1, B) (McGregor, 1912, 1917b; McGregor and MeDonough, 1917).

A portion of the carmine females may be identified as Tetranychus multisetis McGregor (1950). The mating studies of Keh (1952) showed that carmine females referable to Tetranychus bimaculatus are inseparable from T. multisetis from a hereditary viewpoint. The number of setae on the fore tarsus of the female, proximal to the closest duplex setae, was found by Keh to be dependent on the chaetotaxy of the mother, regardless of the chaetotaxy of the mother of the male parent. Davis (1952) also found that the carmine form of T. multisetis interbreeds freely with the carmine form of T. bimaculatus, the tarsal chaetotaxy of offspring being dependent entirely on the mother. T. multisetis, therefore, is not considered to be a valid species.

Actively feeding females in the more northern United States (except for certain greenhouse infestations) are always greenish in basic color (plate 1, A) (Ewing, 1914, and Cagle, 1949). These females always possess only four setae proximad of the first duplex setae on tarsus I. Such females are typical of the two-spotted spider mite as it is usually understood in North America.

The carmine form and the green form of Tetranychus bimaculatus may react differently to acaricides. Neiswander, Rodriguez, and Neiswander (1950) showed that the green form was much more resistant to the chemicals they used, and considerable differences were found by Reynolds, Anderson, and Swift (1952) with a large number of acaricides tested.

Field Recognition. Actively feeding females of Tetranychus bimaculatus are often greenish (plate 1, A) or straw-colored with a large blackish spot on each side near the middle of the body. These females resemble closely those of $T$. atlanticus. However, the colonies quickly spread between the major veins under the cotton leaf, and mite feeding is not conducive to leaf fall as in T. atlanticus. A reddening of the upper surface of the leaf due to feeding is produced more slowly and the coloration is not as pronounced as in T. atlanticus.

Other actively feeding females of Tetranychus bimaculatus are carmine (plate $1, B$ ) in color, thus resembling females of T.tumidus, T. marianae, and $T$. desertorum.

Hosts. Tetranychus bimaculatus is regarded as a serious pest of fruit trees, as well as truck and forage crops. It is also a serious pest of cotton in North America.

Trees such as apple, pear, peach, nectarine, plum, prune, apricot, cherry, walnut, almond, locust, basswood, are all subject to infestation. Many vegetables, berries, hops, and forage crops are also seriously affected. Weeds are common hosts. 

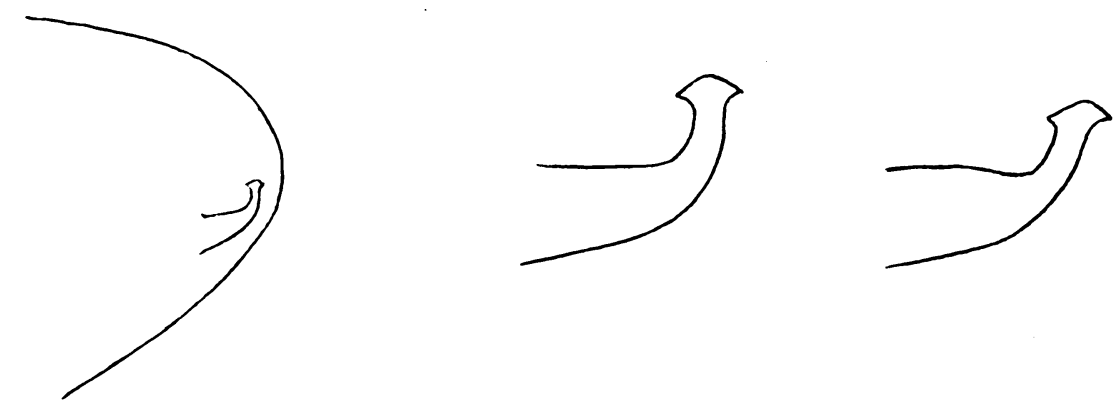

$\boldsymbol{A}$
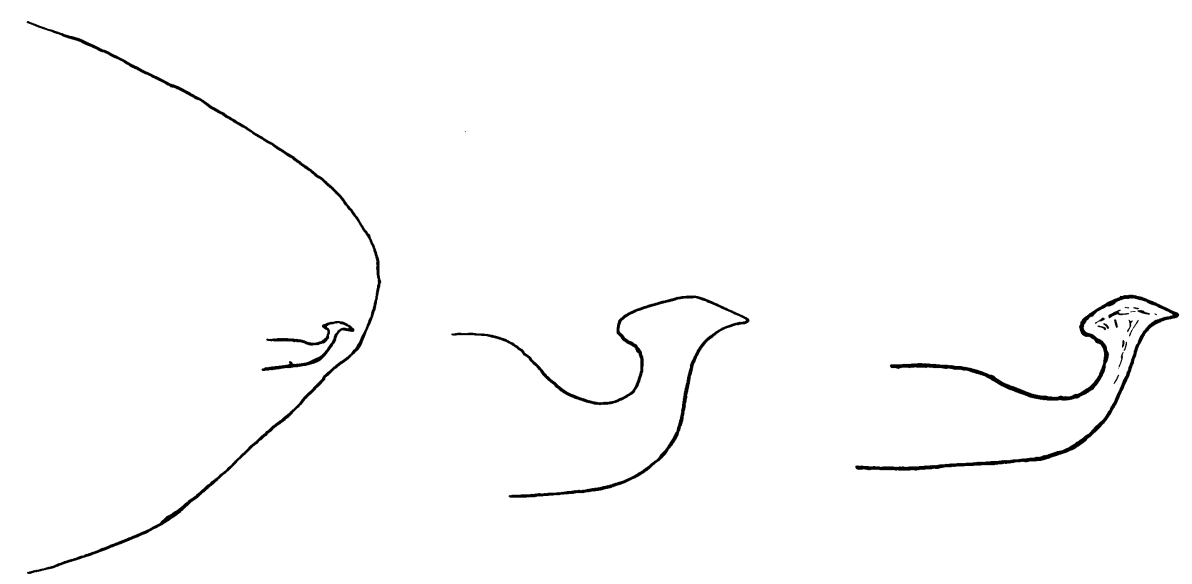

$\boldsymbol{B}$

Fig. 18. Aedeagi: A, of Tetranychus bimaculatus; and B, of T. atlanticus.

Distribution. Tetranychus bimaculatus is widespread throughout most of North America, but it is seldom found in Texas. The carmine form prevails on cotton in the southeastern United States, and it is found also in the Mediterranean region, southern California, and Hawaii. The green form is known throughout most of the United States and is also known from Europe, Australia, and South Africa. 


\section{Tetranychus atlanticus McGregor Atlantic Spider Mite \\ (Figs. 18, B, 19, A)}

Tetranychus atlanticus McGregor, 1941, Ent. Soc. Wash. Proc. 43: 26.

Identification. Females of Tetranychus atlanticus resemble those of many other species of Tetranychus in that longitudinal integumentary striae are formed between both the inner lumbar and the inner sacral setae. The species further resembles $T$. bimaculatus and T. marianae in that the upper duplex setae of tarsus I are distad of the other proximal setae and the empodial spur is rudimentary.
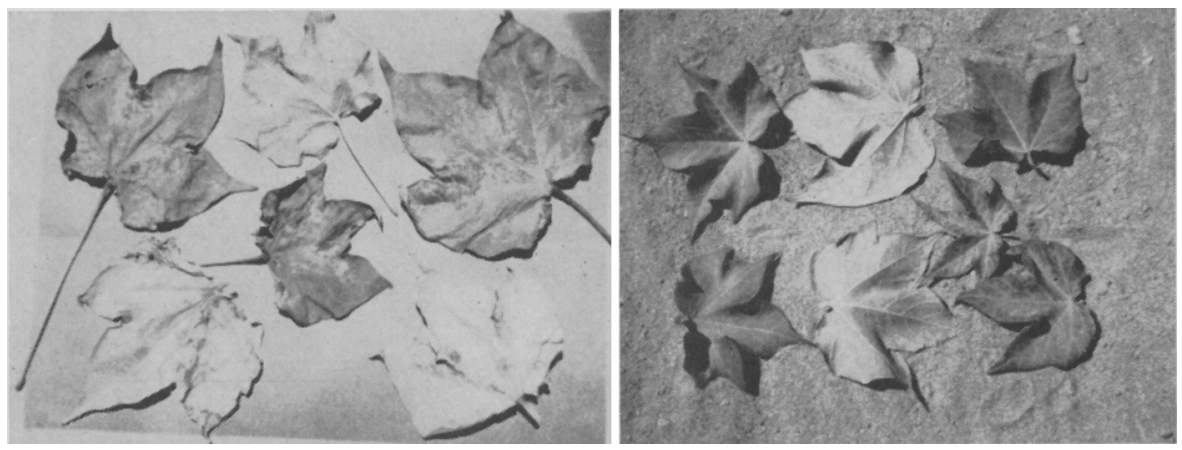

Fig. 19. Feeding injury to cotton leaves: $A$, by Tetranychus atlanticus; and $B$, by $T$. pacificus.

Males must be mounted to differentiate Tetranychus atlanticus from $T$. bimaculatus and T. marianae. The aedeagus of T. atlanticus (fig. 18, B) bears a much larger distal knob.

Field Recognition. Actively feeding females of Tetranychus atlanticus are straw-colored or sometimes greenish with a dark shoulder spot on each side. The colonies of this species are restricted, and a reddish coloration is quickly produced on the upper surface of the cotton leaf by their feeding (fig. 19, $A$ ). Comparatively few individuals will cause the leaves to drop, and bottom leaves are attacked first.

Biological Notes. No detailed studies have been made of the Atlantic spider mite, although it is known to be a serious and widespread pest.

Gordon L. Smith reports that Tetranychus atlanticus was first noted on cotton in California in 1939, the infestations being so unusually early that considerable controversy was raised over its identity. Identifications were not definitely made until 1942 . Prior to $1949, T$. atlanticus was the predominant mite pest of cotton seedlings and small cotton plants in California. However, other species may now also be important early in the season, owing to changes in crop-rotation practices.

Hosts. Tetranychus atlanticus is found primarily on low-growing hosts. Cotton, alfalfa, beans, clover, strawberry, parsley, melons, and eggplant are all commercial crops known to be subject to attack. Infestations are also known from ornamentals such as violet, sunflower, and privet. Less often, 

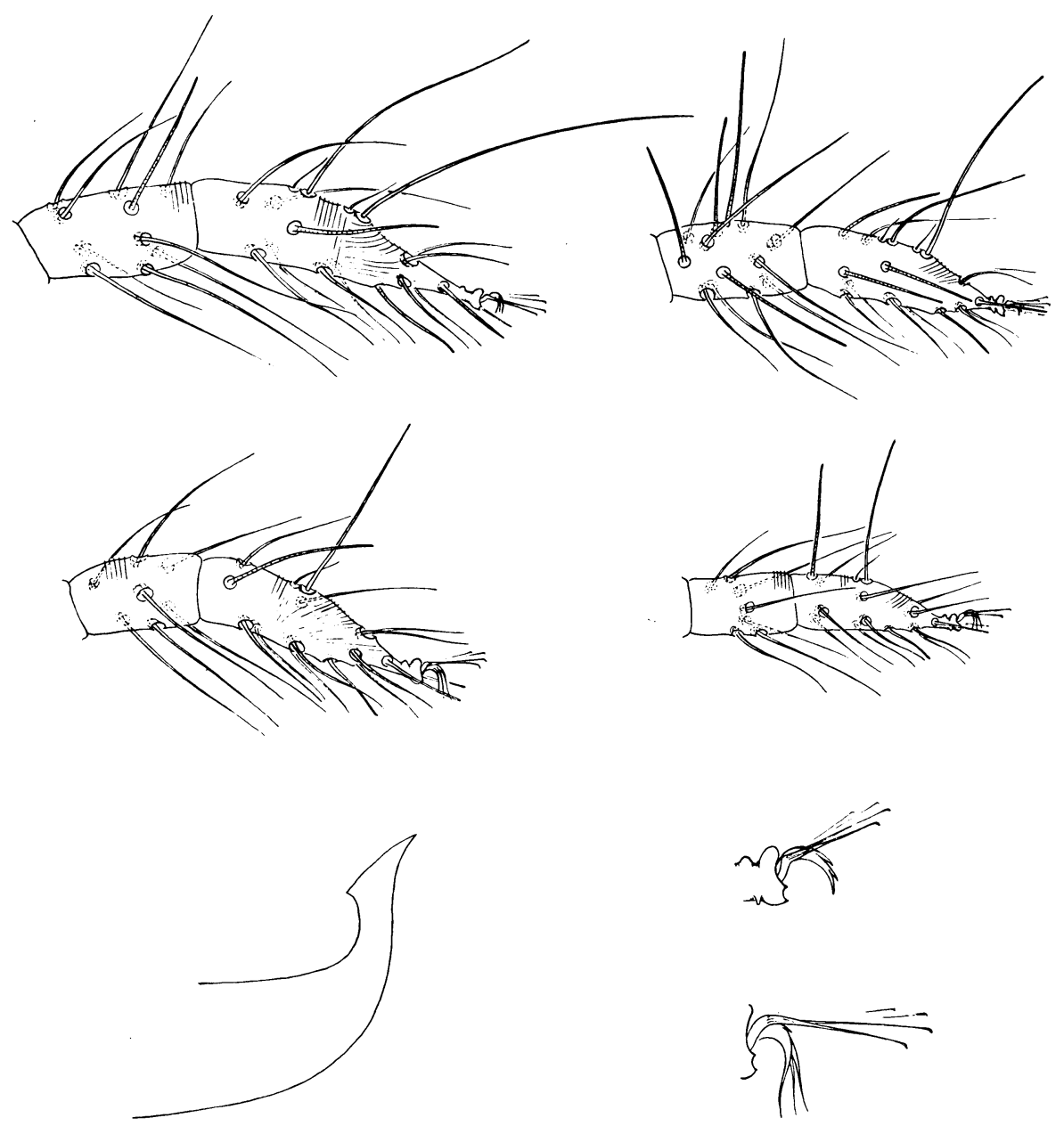

Fig. 20. Tetranychus marianae: Two upper rows, tibiae and tarsi : upper left, of leg I of female; upper right, of leg II of female; center left, of leg I of male; center right, of leg II of male. Bottom row, left, aedeagus; right, tarsal appendages of male, above, of leg I; below, of leg II.

fruit trees such as peach, pear, plum, apple, walnut, and lemon are known to harbor the mites, at least on lower branches.

Distribution. This species is known only from the United States, but it appears to be predominant as a pest in the West. Records include New York, Connecticut, Maryland, Delaware, Virginia, South Carolina, Kentucky, Georgia, Florida, Alabama, Mississippi, Louisiana, Ohio, and Wisconsin in the eastern states; Oregon, Idaho, Utah, and California in the West. It is not known to attack cotton in the area from Texas to eastern Arizona, but it is a primary pest of cotton in California. 


\section{Tetranychus marianae McGregor Tropical Spider Mite}

(Fig. 20)

Tetranychus marianae McGregor, 1950, Amer. Midland Nat. 44: 291.

Identification. The female represents that group of species having a diamond-shaped pattern of integumentary striae in the area between the inner lumbar and inner sacral setae, the duplex setae of tarsus I (fig. 20, top and center rows, left) placed distal to other proximal setae, and the empodial claw rudimentary (fig. 20, bottom row, right).

The aedeagus (fig. 20, bottom row, left) resembles that of Tetranychus bimaculatus, being much smaller than in T.atlanticus; but it is distinctive in having the caudal end of the distal knob forming a slender and acute, somewhat dorsally projecting angulation.

Field Recognition. Females are carmine in color, resembling Tetranychus tumidus, the carmine form of T. bimaculatus, and T. desertorum. For accurate determination, males must be mounted.

Biological Notes. No biological observations have been published.

Hosts. Tetranychus marianae is known to be a pest of cotton. Other hosts include castor bean, passion flower, orchids, Wedelia, and Melanolepis.

Distribution. This species is widespread on Pacific islands; being known particularly from the Marianas and the Marshalls. It occurs also in Nicaragua, the West Indies, the Bahamas, southern Florida, and Argentina.

\section{Tetranychus desertorum Banks}

\section{Desert Spider Mite}

(Figs. 21, 22)

Tetranychus desertorum Banks, 1900, U. S. Dept. Agr. Div. Ent. Tech. Bul. 8: 76. Tetranychus opuntiae Banks, 1908, Ent. Soc. Wash Proc. 10: 36. New synonymy. Tetranychus thermophilus Ewing, 1926, Ent. News 37: 142. New synonymy. Septanychus argentinus MeGregor, 1943, Ent. Soc. Wash. Proc. 45: 176. New synonymy. Septanychus deserticola MeGregor, 1950, Amer. Midland Nat. $44: 321$. New synonymy. Septanychus texazona McGregor, 1950, Amer. Midland Nat. 44: 328. New synonymy.

Nomenclatural Status. Tetranychus desertorum is the oldest name applicable to this spider mite. Topotype males of $T$. opuntiae were collected by William Iglinsky, Jr., and type males of the other species were available for study. Several long series of separate collections were originally responsible for considering deserticola and texazona to be the same species. The aedeagal structure was found to vary between the two types described by McGregor. Septanychus argentinus was originally regarded as representing a separate species because of the more obvious development of the empodial spur in the types. The large series studied from Texas and Arizona shows that this character is variable.

Identification. The female (fig. 21) of Tetranychus desertorum differs from other members of the genus that occur on cotton in that the proximal duplex setae of tarsus I (fig. 22) are more or less in line with the other proximal setae. 


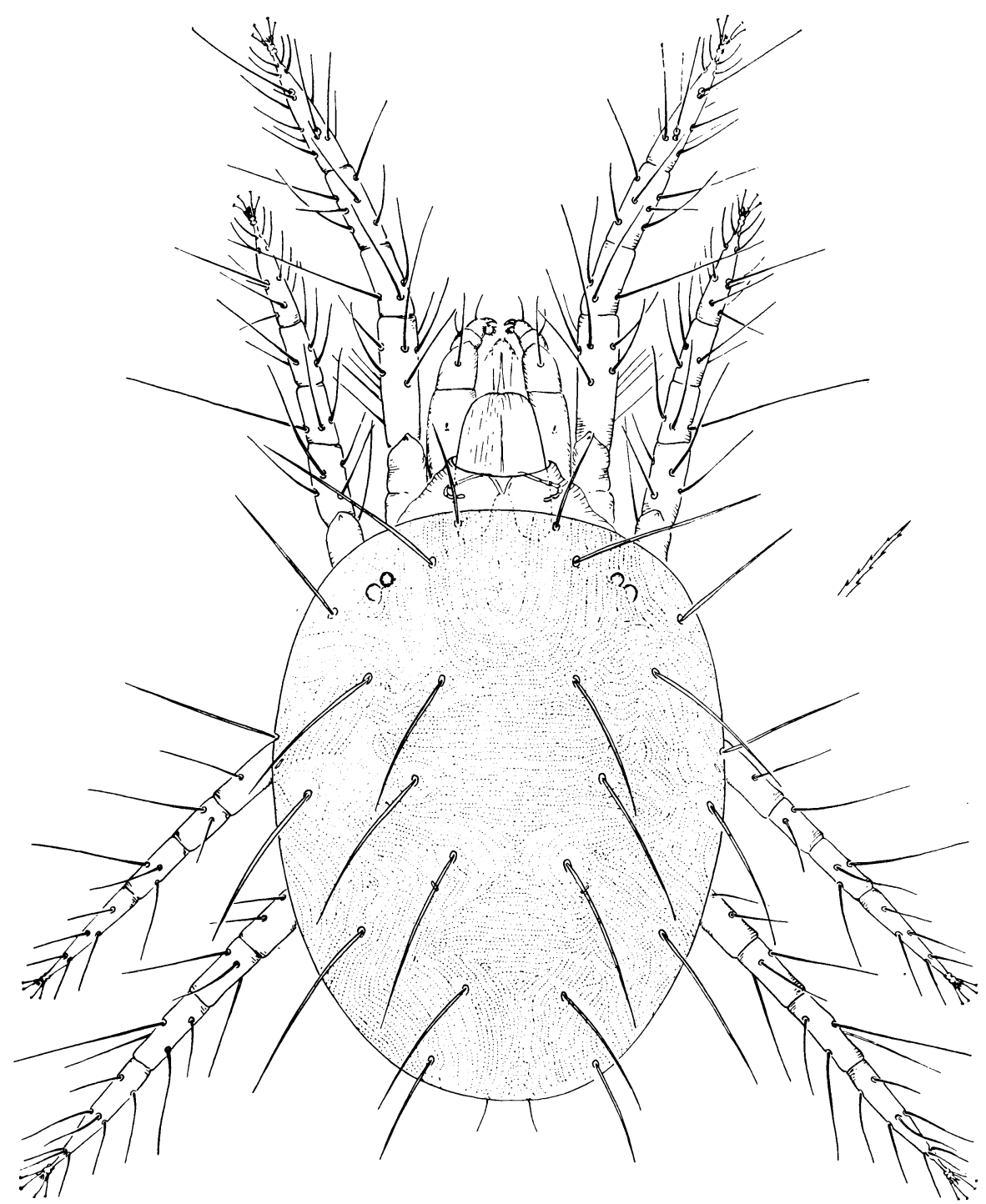

Fig. 21. Tetranychus desertorum: female showing dorsal striae.

The aedeagus (fig. 22) is distinctive in that the dorsal margin of the distal knob is sigmoid.

Field Recognition. Adult females of Tetranychus desertorum are carmine, similar to females of $T$. tumidus, the carmine form of $T$. bimaculatus, and T. marianae; but they are somewhat larger.

Biological Notes. William Iglinsky, Jr., made biological studies of this spider mite, and we hope that his findings will soon be published. 

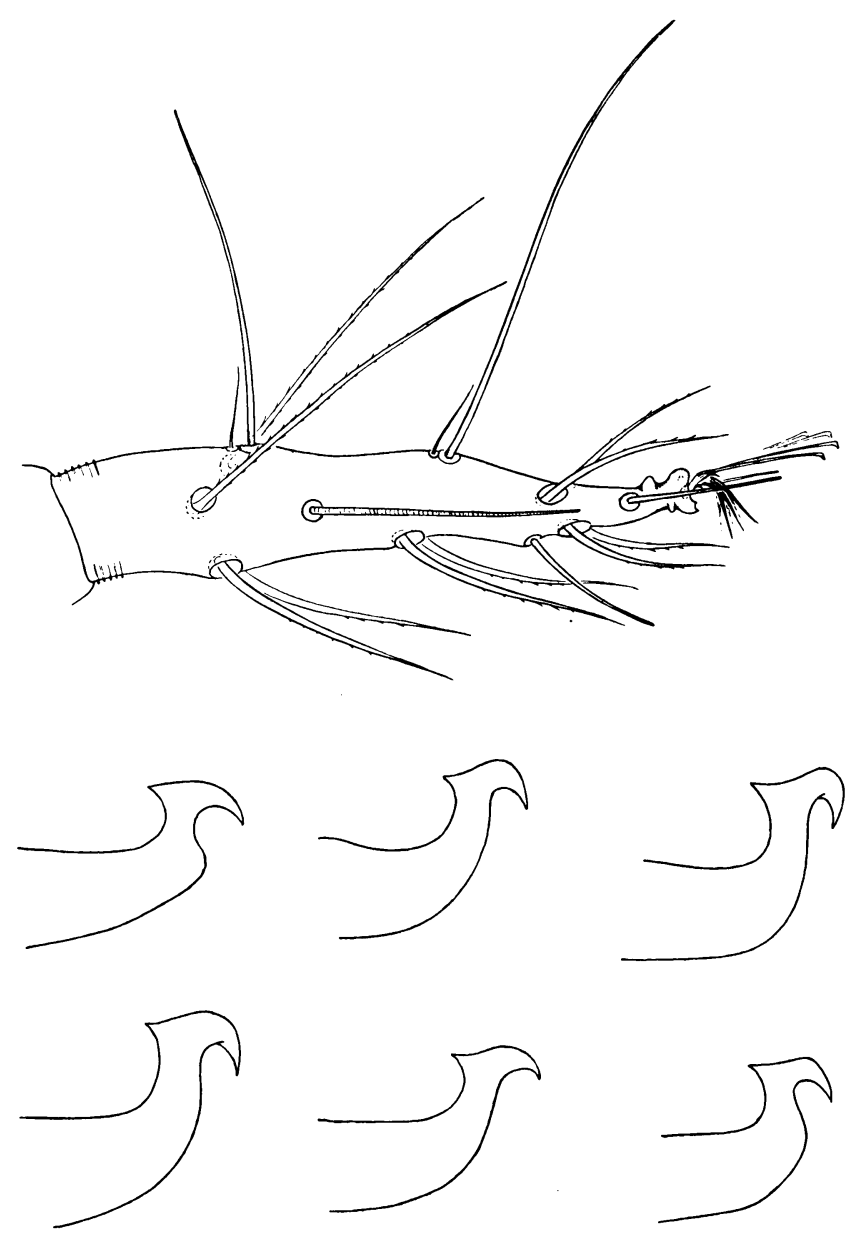

Fig. 22. Tetranychus desertorum: tarsus I of female and aedeagi.

Hosts. Tetranychus desertorum is the dominant mite pest of cotton in Texas, and is of local importance on cotton in other areas. Crops such as melons, cantaloupe, cucumber, celery, carrots, turnips, and alfalfa may be damaged. Wild hosts include creosote bush, grass, wild tomatoes, Stillingia, prickly pear cactus, monkey flower, puncture vine, Eriodictyon, sunflower, and particularly Erigeron canadensis.

Distribution. This species is known from California, Arizona, New Mexico, Texas, Oklahoma, Louisiana, Mississippi, Georgia, South Carolina, and North Carolina in the United States. It is also known from Peru and Argentina in South America. 


\section{Tetranychus tumidus Banks \\ Tumid Spider Mite}

(Fig. 23)

Tetranychus tumidus Banks, 1900, U. S. Dept. Agr. Div. Ent. Tech. Bul. 8: 73.

Tetranychus gloveri Banks, 1900, U. S. Dept. Agr. Div. Ent. Tech. Bul. 8: 76. New synonymy.

Tetranychus antillarum Banks, 1917, Ent. News 28: 194. New synonymy.

Septanychus quinquenychus McGregor, 1919, U. S. Natl. Mus. Bul. 56(2303) : 664.
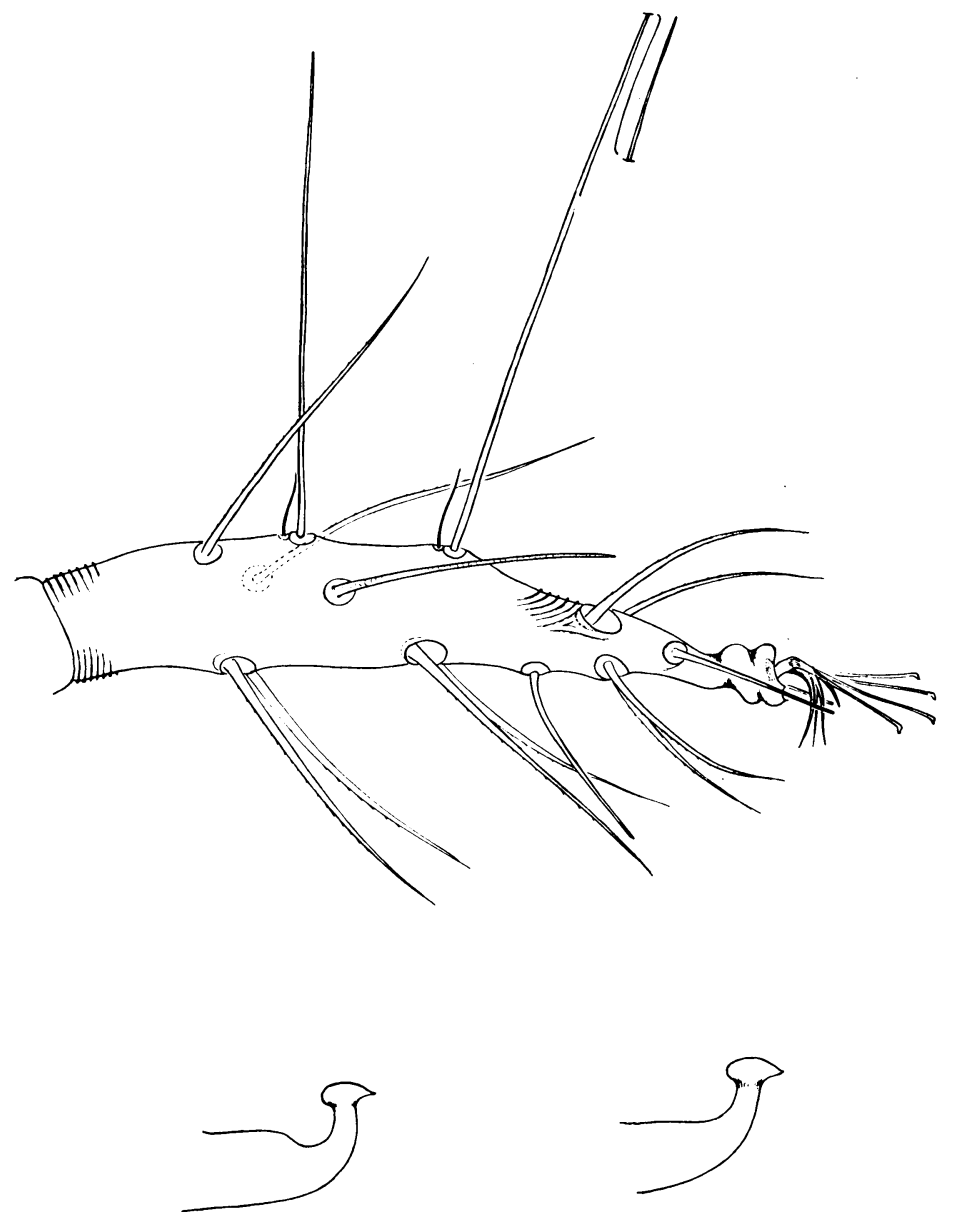

Fig. 23. Tetranychus tumidus: tarsus I of female and aedeagus.

Identification. Adults of Tetranychus tumidus may be differentiated from other species of Tetranychus known from cotton by having a short but obvious empodial spur on all the legs and the proximal duplex setae on tarsus I distad of other proximal setae (fig. 23). The aedeagus is distinctive in that the distal knob is evenly rounded anteriorly and acuminate posteriorly. 
Field Recognition. Adult females of Tetranychus tumidus are carmine, resembling $T$. desertorum, the carmine form of T. bimaculatus, and T. marianae. For accurate determination males must be mounted.

Biological Notes. Roussel et al. (1951) report that in a small field plot test conducted at Baton Rouge, Louisiana, injury to cotton resulting from infestation by Tetranychus tumidus caused a 45 per cent reduction in the amount of seed cotton produced. The injury measurably reduced the vegetative growth. The authors also observed that several characters of the seed and lint were adversely affected.

Hosts. Tetranychus tumidus is a pest of cotton, celery, beans, eggplant, beets, okra, peas, and sweet potato. Other hosts include castor bean, dahlia, morning glory, palms, maranta, milkweed, water hyacinth, water lily, and mint, as well as many types of tropical plants.

Distribution. Tetranychus tumidus is known from Florida, Georgia, South Carolina, Louisiana, and southeastern Texas. It also occurs in the West Indies, and McGregor (1950) records it from Guam. The record by Womersley (1942) of this species from Australia is based on a misidentification.

\section{ACKNOWLEDGMENTS}

We are grateful to Gordon L. Smith of the University of California, who was consulted on many aspects of the spider-mite problem. R. W. Harned of the U. S. Bureau of Entomology and Plant Quarantine, Lauren D. Anderson and Ray F. Smith of the University of California, as well as other entomologists, carefully reviewed the manuscript and offered helpful suggestions. Many of the records from the southeastern United States are based on a survey of cotton mites made by William Iglinsky, Jr., while with the U. S. Bureau of Entomology and Plant Quarantine.

ANDRE, M. MARC

\section{LITERATURE CITED}

1933. Note sur un Tétranyque nuisible au cottonier en Nouvelle-Calédonie. Mus. Hist. CAGLE, L. R. Nat. Paris Bul. (sér. 2), 5: 302-308.

1943. Life history of the spider mite Tetranychus schoenei McG. Virginia Agr. Exp. Sta. Tech. Bul. 87: 1-16.

1949. Life history of the two-spotted spider mite. Virginia Agr. Exp. Sta. Tech. Bul. 113: 1-31.

Davis, Donald W.

1952. Biological studies on three forms of the two-spotted spider mite. Pan-Pacific Ent. 28: $1-6$.

Ewing, H. E.

1914. The common red spider or spider mite. Oregon Agr. Exp. Sta. Bul. 121: 1-95.

FENTON, F. A.

1951. The brown wheat mite Petrobia latens. Jour. Econ. Ent. 44: 996.

GASSER, R.

1951. Zur Kenntnis der gemeinen Spinnmilbe Tetranychus urticae Koch. Schweiz. Ent. Gesell. Mitt. 24: 217-62.

GeIJSKES, D. C.

1939. Beiträge zur Kenntnis der europäischen Spinnmilben (Acari, Tetranychidae), mit besonderer Berücksichtigung der niederlandischen Arten. Wageningen Landbouwhoogesch. Meded. 42 (4) : 1-68. 
Hargreaves, H.

1948. List of recorded cotton insects of the world. 50 p. Commonwealth Institute of Entomology, London.

Hirst, STANLEY

1922. On some new parasitic mites. Zool. Soc. London Proc. 1921: 769-802.

1926. Descriptions of new mites, including four new species of "red spider." Zool. Soc. London Proc. 1926 : 825-41.

KEH, BENJAMIN

1952. Mating experiments with the two-spotted spider mite complex. Jour. Econ. Ent. 45: $308-12$.

LiEnk, S. E., and P. J. Chapman

1951. Orchard mite studies in 1950. Jour. Econ. Ent. 44: 301-6.

McGregor, E. A.

1912. The red spider on cotton. U. S. Dept. Agr. Bur. Ent. Cir. 150: 1-13.

1917a. Descriptions of seven new species of red spiders. U. S. Natl. Mus. Proc. 51: 581$90.7 \mathrm{pl}$.

$1917 b$. The red spider on cotton and how to control it. U. S. Dept. Agr. Farmer's Bul. 831: $1-15$.

1919. The red spiders of America and a few European species likely to be introduced. U. S. Natl. Mus. Proc. 56: 641-79. $6 \mathrm{pl}$.

1942. The taxonomic status of the so-called "common red spider." Ent. Soc. Wash. Proc. 44: 26-29.

1950. Mites of the family Tetranychidae. Amer. Midland Nat. 44(2): 257-420.

McGregor, E. A., and F. L. McDonough

1917. The red spider on cotton. U. S. Dept. Agr. Bul. 416: 1-72.

Neiswander, C. R., J. G. Rodriguez, and R. B. Neiswander

1950. Natural and induced variations in two-spotted spider mite populations. Jour. Econ. Ent. 43: 633-36.

Oudemans, A. C.

1930. Acarologische aanteekeningen CV. Ent. Ber. 8: 157-72.

Pritchard, A. EARL, and EDWARD W. BAKER

1952. A guide to the spider mites of deciduous fruit trees. Hilgardia 21(9): 253-87.

Reynolds, H. T., L. D. Anderson, and J. E. SwifT

1952. Acaricide dusts on vegetable and field crops in southern California, 1949-1950. Jour Econ. Ent. 45: 359-65.

Roussel, J. S., J. C. WeBer, L. D. Newsom, and C. E. SMith

1951. The effect of infestation by the spider mite Septanychus tumidus on growth and yield of cotton. Jour. Econ. Ent. 44: 523-27.

Smith, Gordon L., and Douglas E. Bryan

1951. Mites on cotton-control of spider mites varies with species attacking the plants. California Agr. 5(4): 11, 15.

Ugarov, A. A., and V. V. NikolskiI

1937. K sistematike sredneazyatakogs pautinnovo kleshchika. In: Voprocy Zachehity Khlopchatnika. Sredneaziatskoi Stantsii Zashchaty Rastenii Trudy p. 26-64. (In Russian.)

Womersley, $\mathrm{H}$.

1942. Miscellaneous additions to the acarine fauna of Australia. Roy. Soc. So. Australia Trans. 66: 85-92.

ZACHER, Friedrich

1920. Neue und wenig Bekannte Spinnmilben. Ztschr. f. Angew. Ent. 7: 181-87. 
The journal Hilgardia is published at irregular intervals, in volumes of about 600 pages. The number of issues per volume varies.

Subscriptions are not sold. The periodical is sent as published only to libraries, or to institutions in foreign countries having publications to offer in exchange.

You may obtain a single copy of any issue free, as long as the supply lasts; please request by volume and issue number from:

Publications Office

College of Agriculture

Berkeley 4, California

The limit to nonresidents of California is 10 separate issues on a single order. A list of the issues still available will be sent on request. 